NBSIR 75-786

\title{
The CPSC Road Test of Bicycle Braking Performance -- Kinetic and Error Analyses
}

Leonard Mordfin

Engineering Mechanics Section

Mechanics Division

Institute for Basic Standards

National Bureau of Standards

Washington, D. C. 20234

October 1975

Final Report

Prepared for

Office of Consumer Product Safety

Center for Consumer Product Technology

Institute for Applied Technology

National Bureau of Standards

Washington, D. C. 20234 



\section{THE CPSC ROAD TEST OF} BICYCLE BRAKING PERFORMANCE -. KINETIC AND ERROR ANALYSES

Leonard Mordfin

Engineering Mechanics Section

Mechanics Division

Institute for Basic Standards

National Bureau of Standards

Washington, D. C. 20234

October 1975

Final Report

\section{Prepared for}

Office of Consumer Product Safety

Center for Consumer Product Technology

Institute for Applied Technology

National Bureau of Standards

Washington, D. C. 20234

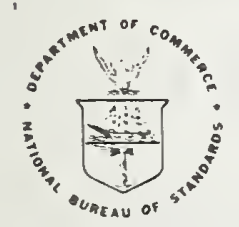

U.S. DEPARTMENT OF COMMERCE, Rogers C. B. Morton, Secretary James A. Baker, III, Under Secretan

Dr. Betsy Ancker-Johnson, Assistant Secretary for Science and Technology

NATIONAL BUREAU OF STANDARDS, Ernest Ambler, Acting Director 
2. SCOPE AND TERMINOLOGY

2.1 The Typical Bicycle

2.2 Brake Characteristics

2.3 Braking Performance

4. ERROR ANALYSIS: PRELIMINARY REMARKS

5. MEASURING THE STOPPING DISTANCE

5.1 Defining the Starting Point

6. REACTION TIME

7. MEASUREMENT AND CONTROL OF INITIAL SPEED

7.1 Measurement

7.2 Control

8. EFFECTS OF PAVEMENT SURFACE

9. UNCERTAINTIES IN THE APPLIED LEVER FORCES

9.1 Kinetic Analysis

9.2 Error Analysis 
13. ERROR ANALYSIS: INTERPRETATIONS AND IMPLICATIONS

13.1 Summary of Individual Error Analyses

13.2 The Measurement System: An Example

13.3 Linear Accumulation of Errors

13.4 Significance of Random and Systematic Errors

13.5 Test-to-Test Variability

13.6 Lab-to-Lab Variability

13.7 Reducing the Effects of Test-to-Test Variability

14.1 Brake Sensitivities

14.2 Optimum Tire/Pavement Friction Coefficients

14.3 Other Kinds of Bicycles

14.4 Other Test Parameters

14.5 Improved Testing Techniques 
THE CPSC ROAD TEST OF BICYCLE BRAKING PERFORMANCE

--KINETIC AND ERROR ANALYSES

Leonard Mordfin

\begin{abstract}
The Consumer Product Safety Commission has promulgated a safety standard for bicycle braking systems based on the stopping distances achieved in road tests under specified conditions. This report presents an error analysis of the test method, for the Commission's use in justifying or modifying the test criteria. The error analysis is based on experimental data, for the most part, and on theoretical principles where sufficient data are lacking. The theory, a kinetic analysis of the bicycle braking process, is included in the report together with proposed definitions of terms intended to quantify important aspects of bicycle braking performance.
\end{abstract}

The error analysis produced estimates of rather large $1 a b-t o-1 a b$ and test-to-test variabilities to be expected from the test method. These, in turn, were found to be principally dominated by errors resulting from an incorrect overweight-rider allowance specified by the Commission, and by variations in rider reaction times, respectively. Suggestions are made for more accurate methods of accommodating variations in rider mass, for reducing the effects of the test-to-test variability, and for reducing the danger of pitchover in the performance of the road test.

Key Words: Bicycle brakes; brakes, bicycle; dynamics, bicycle; error analysis; friction, tire/pavement; kinetics, bicycle; measurements, bicycle braking; pitchover; standards, bicycle safety; test method, bicycle.

\title{
INTRODUCTION
}

In July 1974, the Consumer Product Safety Comission (CPSC) promulgated a regulation that established safety requirements for bicycles [1]. This regulation, together with a subsequent amendment [2] (which will hereinafter be referred to as the Bicycle Safety Regulation) includes a requirement for braking performance tests to be carried out on bicycles equipped 
with handbrakes. $*$ While the test criteria vary somewhat depending upon a bicycle's gear ratio, the size of the rider, etc., the basic test calls For the bicycle, with a $68.1 \mathrm{~kg}(150-1 \mathrm{~b})$ rider, to be stopped from a speed of $24 \mathrm{~km} / \mathrm{h}$ ( $15 \mathrm{mph}$ ) within a distance of $4.57 \mathrm{~m}$ (15 ft), with forces of not more than $178 \mathrm{~N}$ (40 $\mathrm{lbf}$ ) applied to the handbrake levers.

Several bicycle manufacturers have objected to this requirement (see, for example, $[3,4]$ ). The manufacturers claim that errors. inherent in the test procedure lead to a large spread, or variability, in the test results, even under closely controlled, nominally identical, test conditions. In order to insure that a bicycle will pass the road test, they state, its braking system would have to be overdesigned and this, it is contended, increases the bicycle's susceptibility to accidents resulting from pitchover. The manfacturers cite a similar test method which is under development by a working group of the International Organization for Standardization (ISO) which, in view of the observed variability of test results, specifies a less-stringent stopping-distance requirement $(5.5 \mathrm{~m}, 18 \mathrm{ft})$.

This report presents the results of a study which was devoted, primarily, to an analysis of the errors that are encountered in conducting the braking performance test. It is thought that, with definitive information of this kind, certain allowances in the test criteria could be stipulated which would resolve the differences between the Commission and the manufacturers. In carrying out the error analysis it was found that while the effects of certain test parameters could be examined through the use of available experimental data, the effects of others could only be assessed theoretically. Therefore, a two-dimensional kinetic analysis of the braking process was developed so that all of the relevant test parameters could be examined critically. The kinetic analysis also enabled the pitchover problem to be addressed briefly.

Since, clearly, all bicycles and all braking systems could not be studied, some generalizations regarding bicycle characteristics and braking performance are set forth at first. These, together with subsequent results, effectively delineate the boundaries of applicability of the error analysis.

This study was carried out in the Engineering Mechanics Section of the National Bureau of Standards (NBS) for the NBS Office of Consumer Product Safety.

*For bicycles equipped with other types of brakes see Section 14.3 . 


\section{SCOPE AND TERMINOLOGY}

The symbols used in this report are defined in the Appendix. In addition, each symbol is defined where it is first used, either in the text or by reference to an associated figure.

\subsection{The Typical Bicycle}

There are a great many different types, styles and sizes of bicycles on the market today. It would be a virtually impossible task to analyze each one. Therefore, most of the calculations carried out in this study were limited to what will hereafter be referred to as "the typical bicycle". The characteristics of this bicycle, which are given in Table 1, represent approximate averages of the characteristics of fifty-two different, real bicycles. (The basis upon which the coordinates of the center of gravity (cg) were selected is given later in Section 10.1).

The rationale for using the typical bicycle in most calculations is quite obvious. As mentioned above, the error analysis may be used to establish allowances in the test criteria. These allowances, if based on the typical bicycle, will, strictly speaking, be correct only for bicycles which are similar to the typical bicycle. For other bicycles they can be too large or too small. For bicycles which have characteristics which enable them to stop more easily than the typical bicycle (e.g., less mass, lower cg) the allowances will be larger than necessary. This is not a serious problem since these bicycles, being easier to stop, are not the ones which the test method is intended to identify. On the other hand, the allowances would be too small for bicycles which are more difficult to stop than the typical bicycle. This would, of course, make it more difficult for these bicycles to pass the performance test and thereby help to identify them.

\subsection{Brake Characteristics}

If a force $\mathrm{P}$ is applied to a handbrake lever at a specified point and in a specified direction, the brake pads are thereby caused to exert a squeezing force $Q$ on the wheel rim. Let

$$
\mathrm{Q}=\mathrm{mP}
$$

where $m$ is the mechanical advantage, which depends primarily on the lever ratios of the handbrake lever and the caliper brake assembly. If the wheel is rotating, the squeezing force $Q$ produces a tangential force $\mathrm{F}_{\mathrm{b}}$ on the wheel rim which tends to retard the rotation. Thus,

$$
F_{b}=\nu Q
$$


where $v$ is the coefficient of friction between the brake pads and the wheel rim. From these two expressions it is seen that

$$
F_{b}=\nu m P
$$

In a real brake system $v m$ is not constant because of friction and play in the brake linkage, accumulation of foreign matter on the brake pads and wheel rim, and so on. Nevertheless, the quantity

$$
\mathrm{z}=\nu \mathrm{m}=\frac{F_{b}}{\mathrm{P}}
$$

is a meaningful parameter which describes the brake sensitivity. In this context, a sensitive brake system is one which exerts a strong retarding force to a rotating wheel when a given force is applied to the handbrake lever.

Further discussion of brake sensitivity is given in Section 14.1 .

\subsection{Braking Performance}

While brake characteristics and bicycle characteristics can be discussed separately, as above, the effectiveness of a given brake system depends upon the characteristics of the bicycle it is intended to serve. In other words, a given brake system which may be adequate for one bicycle may be entirely inadequate for another. This leads to the concept of braking capability, $B$, which is intended to provide a measure of the effectiveness of a given brake system on a given bicycle.

In order to quantify braking capability it is helpful to have some standard of braking performance against which it may be compared. Such a standard is provided by the CPSC braking performance test. Let marginal braking capability, $B=1$, be defined as that level of braking performance which enables a bicycle to satisfy the CPSC braking performance test with nothing to spare. Stated more precisely,

A bicycle's brake system exhibits marginal braking capability when an average $68.1-\mathrm{kg}(150-1 \mathrm{~b})$ test rider brings it to a stop on a specified pavement, from a speed of $24 \mathrm{~km} / \mathrm{h}$ (15 mph), in a distance of exactly $4.57 \mathrm{~m}(15.0 \mathrm{ft})$, by applying $178 \mathrm{~N}$ (40 $1 \mathrm{bf})$ to the handbrake levers.

(The characteristics of an "average" test rider and the "specified" pavement will be developed later.) If the brake system which exhibits marginal 
braking capability has a brake sensitivity $Z_{0}$, then the braking capability of any other brake system on the same bicycle is, simply,

$$
B=\frac{Z}{Z_{0}}
$$

where $\mathrm{Z}$ is the brake sensitivity of the other brake system.

\section{KINETIC ANALYSIS}

The equations of motion of a bicycle/rider system can, in principle, be derived from a consideration of only the external forces acting on the system. These external forces consist of the reactions at the tire/pavement interfaces and wind resistance. This approach is inadequate for present purposes, however, since it provides no direct understanding of the role played by the braking forces themselves, i.e., the retarding forces applied by the brake pads. Therefore, in order to obtain such understanding, the system is examined in three parts: the rear wheel, the front wheel, and the bicycle frame-plus-rider combination. For simplicity, wind resistance, which has a second-order effect on bicycle braking, is ignored at first and then analyzed as a perturbation of the principal system later on (Section 12).

Free-body diagrams of the rear wheel, the front wheel and the frame/rider combination are given in Figures 1, 2 and 3 , respectively. In Figures 1 and 2 the small difference between the outer radius of the tire, and the radius of the wheel rim at which the brake pads make contact, has been ignored for simplicity. Rolling friction in the wheel bearings has been neglected. In Figure 3 the rider is not shown, for convenience in drawing, but the force of gravity which acts upon him is included in the total force of gravity acting at the center of gravity of the frame/rider combination.

Using D'Alembert's principle, the three equations of equilibrium. for the rear wheel, in the vertical, horizontal and rotational directions, respectively, are

$$
\begin{aligned}
& R_{r}+F_{b r} \sin \theta_{r}-F_{y r}-W_{W}=0, \\
& f_{r}+F_{b r} \cos \theta_{r}-F_{x r}-\frac{W_{W}}{g} a=0, \\
& f_{I}-F_{b r}+\frac{W_{W}}{g} a=0,
\end{aligned}
$$


where, in the third equation, it has been assumed that the wheel rolls without slipping on the pavement and that the mass of the wheel is concentrated at its outer periphery. That is,

$$
\alpha=\frac{2 a}{D}
$$

and

$$
I=\frac{W_{w} D^{2}}{4 g}:
$$

In general, the wheel may be expected to rotate without slipping on the pavement if

$$
\frac{f_{r}}{R_{r}}<\mu
$$

where $\mu$ is the coefficient of friction at the tire/pavement interface.

If the wheel is locked, and skids without rotating, then

$$
\alpha=0
$$

and

$$
\mathrm{f}_{\mathrm{r}}=\mu \mathrm{R}_{\mathbf{r}}
$$

so Equation (5A) becomes

$$
\mathrm{f}_{\mathrm{r}}=\mu \mathrm{R}_{\mathrm{r}}=\mathrm{F}_{\mathrm{br}} \text {. }
$$

(Note that the value of $\mu$ which determines whether or not a rotating wheel will lock and skid is the coefficient of static friction, while the value which determines the retarding force on a locked, skidding wheel is the coefficient of sliding friction. The difference between these two values has been ignored as representing a refinement in the analysis which is not warranted for present purposes.)

Following the same procedure, the equations for the front wheel are

$$
R_{r}-F_{b f} \sin \theta_{f}-F_{y f}-W_{W}=0 \text {, }
$$




$$
\begin{aligned}
& f_{f}+F_{b f} \cos \theta_{f}-F_{x f}-\frac{W}{g} a=0, \\
& f_{f}-F_{b f}+\frac{W}{g} a=0,
\end{aligned}
$$

when the wheel rolls without slipping. If the wheel is locked, and skids without rotating, then Equation ( $8 \mathrm{~A}$ ) becomes

$$
f_{f}=\mu R_{f}=F_{b f} \text {. }
$$

Using D'Alembert's principle again, the equations of equilibrium for the rider-frame combination are

$$
\begin{aligned}
& F_{y r}+F_{y f}-F_{b r} \sin \theta_{r}+F_{b f} \sin \theta_{f}-\left(W_{f}+W_{r}\right)=0, \\
& F_{x r}+F_{x f}-F_{b r} \cos \theta_{r}+F_{b f} \cos \theta_{f}-\frac{W_{f}+W_{r}}{g} a=0,
\end{aligned}
$$

$$
\begin{aligned}
& F_{y r}(L-q)-F_{y f} q+\left(F_{x r}+F_{x f}\right) h+F_{b r}\left[\frac{D}{2}-h \cos \theta_{r}-(L-q) \sin \theta_{I}\right] \\
& +F_{b f}\left[\frac{D}{2}-h \cos \theta_{f}-q \sin \theta_{f}\right]=0 .
\end{aligned}
$$

The cg location of the bicycle/rider system ( $(, H)$ is slightly different from that of the frame/rider combination $(q, h)$ because of the mass of the bicycle wheels. It is easily shown that

$$
h=\frac{W_{b}+W_{r}}{W_{f}+W_{r}}\left(H-\frac{D}{2}\right)
$$

and

$$
q=\frac{\left(w_{b}+w_{r}\right) l-w_{w} L}{w_{f}+w_{r}}
$$

where $l$ is the distance of the $\mathrm{cg}$ of the bicycle/rider system aft of the front wheel axis, $H$ is the height of the $c g$ of the bicycle/rider system above the pavement, and

$$
\mathrm{W}_{\mathrm{b}}=\mathrm{W}_{\mathrm{f}}+2 \mathrm{~W}_{\mathrm{W}}
$$

Increasing the deceleration causes the vertical reaction force at the rear wheel, $R_{r}$, to diminish. The condition $R_{r}=0$ represents the thres- 
hold of the instability condition which is commonly referred to as "pitchover".

The general solution of Equations ( 3 ) through (11) is

$$
\frac{a}{g}=\frac{f_{r}+f_{f}}{W_{b}+W_{r}}
$$

and

$$
\mathrm{R}_{\mathrm{f}}=\mathrm{W}_{\mathrm{b}}+\mathrm{W}_{\mathrm{r}}-\mathrm{R}_{\mathrm{r}} \text {. }
$$

Specific solutions for the several cases of rolling and/or locked wheels follow. The substitutions represented by Equations (12) and (13) have been made so that the solutions are given in terms of the cg location of the bicycle/rider system.

Case I. With gentle-to-moderate braking on pavements which offer moderateto-high coefficients of friction, both wheels of the bicycle roll without slipping. Under this condition

$$
\begin{gathered}
\frac{a}{g}=\frac{F_{b r}+F_{b f}}{W_{b}+W_{r}+2 W_{w}}, \\
f_{r}=F_{b r}-w_{w} \frac{a}{g} \quad\left(f_{r}<\mu R_{r}\right), \\
f_{f}=F_{b f}-W_{w} \frac{a}{g} \quad\left(f_{f}<\mu R_{f}\right),
\end{gathered}
$$

and

$$
R_{r}=\left(w_{b}+w_{r}\right) \frac{\ell}{L}-\left[\left(w_{b}+w_{r}\right) \frac{H}{L}+w_{w} \frac{D}{L}\right] \frac{a}{g} \cdot
$$

If $F_{b r}=F_{b f}$ (that is, if the brake sensitivities of the front and rear brakes are levers) then this condition exists as long as

$$
0 \leq \frac{a}{g} \leq \frac{\mu \frac{\ell}{L}}{\frac{1}{2}+\mu\left[\frac{H}{L}+\frac{1}{2} \frac{W_{w}}{W_{b}+W_{r}}\left(1+\frac{D}{L}\right)\right]} .
$$

Pitchover will not occur while both wheels roll without slipping. 
Case II. There is a range of decelerations in which the front wheel rolls without slipping while the rear wheel rolls and slips simultaneously. If $\mathrm{F}_{\mathrm{br}}=\mathrm{F}_{\mathrm{bf}}$ this range is

$$
\frac{\mu \frac{\ell}{L}}{\frac{1}{2}+\mu\left[\frac{H}{L}+\frac{1}{2} \frac{W_{W}}{W_{b}+W_{r}}\left(1+\frac{D}{L}\right)\right]}<\frac{a}{g}<\frac{\mu \frac{\ell}{L}}{\frac{1}{2}+\left[\frac{H}{L}+\frac{W_{W}}{W_{b}+W_{r}} \frac{D}{L}\right]}
$$

This range is quite narrow and need not be considered further.

Case III. With moderate-to-hard braking on pavements which offer moderateto-high coefficients of friction, the front wheel rolls without slipping while the rear wheel skids without rolling. Under this condition

$$
\begin{aligned}
& \frac{a}{g}=\frac{F_{b f}+\mu\left(w_{b}+w_{r}\right) \frac{l}{L}}{W_{b}+W_{r}+W_{w}+\mu\left[\left(W_{b}+W_{r}\right) \frac{H}{L}+\frac{1}{2} W_{w} \frac{D}{L}\right]}, \\
& f_{f}=\frac{F_{b f}\left(W_{b}+W_{r}\right)-\mu W_{W} R_{r}}{W_{b}+W_{r}+W_{w}} \quad\left(f_{f}<\mu R_{r}\right),
\end{aligned}
$$

and

$$
R_{r}=\left(W_{b}+W_{r}\right) \frac{\ell}{L}-\left[\left(w_{b}+w_{r}\right) \frac{H}{L}+\frac{1}{2} W_{w} \frac{D}{L}\right] \frac{a}{g} \cdot
$$

This condition exists as long as

$$
\frac{\mu \frac{\ell}{L}}{\frac{1}{2}+\mu\left[\frac{H}{L}+\frac{W_{W}}{W_{b}+W_{r}} \frac{D}{L}\right]} \leq \frac{a}{g} \leq \mu
$$

and

$$
\frac{a}{g}<\frac{\frac{l}{L}}{\frac{H}{L}+\frac{1}{2} \frac{W_{W}}{W_{b}+W_{r}} \frac{D}{L}}
$$

If the deceleration exceeds the latter condition (24) pitchover will occur. 
Case IV. On pavements offering low coefficients of friction, or with hard braking on pavements which offer moderate coefficients of friction, both wheels of the bicycle skid without rolling. Under this condition

$$
\frac{\mathrm{a}}{\mathrm{g}}=\mu
$$

and

$$
R_{r}=\left(W_{b}+W_{r}\right)\left(\frac{\ell}{L}-\frac{H}{L} \frac{a}{g}\right)
$$

This condition exists as long as

$$
\frac{\mathrm{a}}{\mathrm{g}}<\frac{\ell}{\mathrm{H}}
$$

If the deceleration exceeds the latter condition pitchover will occur.

With sufficient braking capability, Equation (25) represents the maximum possible deceleration which bicycle/rider systems can attain on a given pavement, and Equation (27) represents the maximum possible deceleration which a given bicycle/rider system can attain on any pavement.

\section{ERROR ANALYSIS: PRELIMINARY REMARKS}

There are many parameters which influence the results of the CPSC brake performance test. Some of these parameters such as, for example, the rider's reaction time*, are relatively uncontrollable and the stopping distances, in any series of tests, will reflect this. Other parameters, such as the tire/pavement friction coefficient, are reasonably controllable but, since different test courses offer different coefficients, different stopping distances will be obtained even with the same bicycle/rider system. Thus, all of the pertinent parameters are seen to contribute to a variability of test results. But, without further information, no single test result can be described as being more correct than any other and, therefore, it is meaningless to speak of the error in any given test result.

However, if a predetermined set of parametric values were postulated as being the "correct" values, then the stopping distance obtained with these parametric values and a given bicycle could be denoted as the true

*Reaction time is defined later as the interval between the instant at which the rider first begins actuating the handbrake levers and the instant at which the prescribed force levels are reached. 
or correct stopping distance for this bicycle. In this vein, the variations in stopping distance, which arise from variations of the pertinent parameters, can properly be temed "errors" if they are expressed as deviations from the correct stopping distance.

These errors, like those encountered in most measurement processes, fall into two categories. A systematic (or bias) error is one that is characteristic of the measurement system which, in this case, includes the instrmentation, the test course and the wind as well as the bicycle/rider system. If a series of tests were conducted with a given system the systematic errors would not change from test to test and, in principle at least, the magnitudes of these errors can be determined.

A random error, on the other hand, is typified by a test-to-test variability and cannot be estimated, except within broad limits, prior to any given test. The average random error experienced in a number of tests, however, tends toward zero as the number of tests increases.

In the absence of adequate data from a well-planned test program it is often difficult to determine whether a given error is systematic or random, or whether it contains components of both. In such cases this detemination, if it is to be made at all, must sometimes be based on little more than an educated guess. Within this context, the various errors involved in the performance of the road test are analyzed in the following eight sections of this report.

Each section is devoted to the errors which arise from the variability of a single parameter or a set of related parameters. Thile the order in which the parameters are treated may appear to be haphazard, this is not entirely the case. The effects of several of the parameters were found to be dependent on others, and so the order is that which enabled each analysis to build upon the findings of prior ones. As it turned out, the first few error analyses are based primarily on available experimental data while the later ones rely chiefly on the kinetic analysis presented in the previous section.

\section{MEASURING THE STOPPING DISTANCE}

"A bicycle equipped with only handbrakes shall... have a stopping distance of no greater than 4.57 m $(15 \mathrm{ft})$...

"The bicycle shall be ridden over a ...test course and, after attaining the specified ground speed, shall be stopped by the rider... The stopping distance shall be measured" [Bicycle Safety Regulation].

The state-of-the-art in length measurements is more than adequate for the needs of the braking performance test. The uncertainties involved 
in measuring the length of a straight 1 ine segment between two points are very small and need not be considered further. However, problems arise because the starting point is not rigorously defined and because the path over which the bicycle travels, in coming to a stop, may not be straight.

\subsection{Defining the Starting Point}

The brakes are applied, by the rider, through the use of the handbrake levers. What instant in the process of brake application corresponds to the starting point for the measurement of stopping distance? Is it the instant at which the actuation of the brake lever begins? Is it the instant at which the brake pads contact the wheel rim? Or is it the instant at which the force applied to the brake lever reaches its maximum or prescribed magnitude?

If the starting point is defined as the instant at which the force applied to the lever reaches its maximum or prescribed magnitude then some braking will be achieved before this instant and a gradual application of force could result in the measurement of very short stopping distances, even with inefficient braking systems. This would defeat the purpose of the test.

If the starting point is defined as the instant at which the brake pads contact the rim then the distance traveled by the bicycle while the slack in the brake system is being overcome is not included in the stopping distance. Yet this is an important consideration in the safety of the braking system in the sense that a large amount of slack degrades a rider's ability to stop quickly in an emergency situation.

On the basis of this reasoning it is postulated that the starting point, for the measurement of stopping distance, is the point corresponding to the instant of brake lever actuation. But which brake, the front or the rear? In a hard stop, with both brakes actuated, there is a substantial dynamic mass transfer of the center of gravity of the bicycle/rider system toward the front of the bicycle. This generally results in skidding of the rear wheel and most of the braking action is achieved through the front wheel brake. Recognizing this, the ISO has taken the position that the road test should be declared invalid if the front brake is not applied first $[5,6]$. However, this approach appears to compromise the usefulness of the test; in an emergency situation in which a rider is seeking maximum braking he can hardly be expected to exercise that degree of mental control which would be required to consciously apply the front brake first. This analysis is, therefore, based on the postulate that the starting point for the measurement of stopping distance is that point corresponding to the location of the bicycle at the instant that the first brake lever actuation begins. 
This is consistent with the method used for evaluating the braking performance of motorcycles [7].

\subsection{Locating the Starting Point}

Having defined the starting point, it remains to locate it. Two methods have been used rather widely. In the first method a starting line is painted on the pavement and the rider is required to actuate the brakes as the front wheel of the bicycle crosses the line. Tests conducted by one manufacturer at a nominal bicycle speed of $24 \mathrm{~km} / \mathrm{h}$ (15 mph) have shown that, in general, the rider is able to commence brake actuation within $\pm 0.3 \mathrm{~m}( \pm 1 \mathrm{ft})$ of the line. The average of six "good" runs fell only $0 . \overline{0} 2 \mathrm{~m}(0 . \overline{0} 7 \mathrm{ft})$ before the line [8]. Tests by a second manufacturer at the same nominal speed showed a spread of $+0.6 \mathrm{~m}( \pm 2 \mathrm{ft})$ with the average of twenty runs falling $0.05 \mathrm{~m}(0.2 \mathrm{ft})$ past the line [9].

These data suggest that the stopping distance measured by this method in any given test may be in error by up to $\pm 0.6 \mathrm{~m} \mathrm{(} \pm 2 \mathrm{ft})$, while the average stopping distance measured in a large number of tests may be in error by only $\pm 0.05 \mathrm{~m}( \pm 0.2 \mathrm{ft})$. These errors are principally random, although they may contain a systematic component reflecting a subconscious bias on the part of the rider.

In the second method, which is more widely used at the present time, actuation of the brake lever operates a device which propels a marker to the pavement. A variety of techniques of this kind have been used, including:

(a) a spring-loaded metal rod treated with a marking substance is released by a spring-loaded trigger pin upon actuation of the brake lever $[10]$;

(b) a chalk pellet is propelled by a fuze that is electrically energized through a switch which operates upon actuation of the brake lever [11];

(c) a chalk cartridge is propelled by an explosively fired gun upon actuation of the brake lever [12];

(d) an electromagnetically activated paint gun is disengaged by a trip switch upon actuation of the brake lever $[8,13]$;

(e) a charge of colored paste is fired with a pneumatic marker gun upon actuation of the brake lever, which opens a pneumatic valve to a reservoir of compressed air [9].

Clearly, some error is involved in the use of this method because (1) there is some delay, due to electrical or mechanical causes, between the instant of actuation of the brake lever and the instant of firing 
and (2) the bicycle -- and the marker -- travel forward at the test speed during the interval between firing of the marker and its impact on the pavement. The latter part of the error may be rendered negligible by assuring that the marker is propelled vertically, at high velocity, from a point close to the pavement. The delay between lever actuation and actual firing may not be negligible. For the chalk gun (item (c) above), limited data [14] indicate that the delay is approximately 0.025 seconds which, at a bicycle speed of $24 \mathrm{~km} / \mathrm{h}$ ( $15 \mathrm{mph}$ ); is equivalent to a forward distance of approximately $0.17 \mathrm{~m}(0.6 \mathrm{ft})$. Data for the paint gun (item (d) above) suggest that the forward distance could be reduced to approximately $0.1 \mathrm{~m}(0.3 \mathrm{ft})$ with suitably powered electromagnets [8].

It would appear that the error involved in all of these techniques is a systematic one which, with good equipment, should be very repeatable. From the above data it is estimated that, in general, this error may be up to $-0.2 \mathrm{~m}(-0.7 \mathrm{ft})$. (The minus sign indicates that the measured stopping distance is less than the correct stopping distance.)

When the marker strikes the pavement it leaves a spot, rather than a point. This introduces a further uncertainty in the measurement of stopping distance, which is estimated to be approximately \pm 0.02 $\mathrm{m}( \pm 0.07 \mathrm{ft})$. This uncertainty comprises a random error.

\subsection{Straightness of the Bicycle Path}

When the bicycle brakes are applied in the road test, the rear wheels generally lock and commence to skid on the pavement. In this situation the rear wheels lose stability and, if the bicycle is not moving on a straight path, a certain amount of lateral breakaway, or side skid, may occur [15]. In correcting for this, either consciously or subconsciously, the rider causes the bicycle to track a crooked path in coming to a stop. The energy dissipated in the brakes and at the tire/pavement interfaces depends upon the actual distance traveled, yet the stopping distance is invariably measured over a straight line between the starting line or starting point and the end point. Thus, insofar as the bicycle does not track a straight path, the measurement of the stopping distance is in error. This problem has resulted in recommendations that road tests be invalidated when excessive side skid or loss of control occurs $[5,12]$. But how much is excessive?

A few exploratory tests were carried out at NBS in which a pressurized container of liquid was used to mark the trail of a bicycle as it was brought to a stop under the prescribed test conditions. It was found that the path is similar to a sinusoid having between two and three cycles. In some cases the double amplitude of the sinusoid was nearly $0.3 \mathrm{~m}$ ( $1 \mathrm{ft}$ ) although, in general, it was less than half of this. Considering a net (straight-1ine) stopping distance of 4.57 $m(15.0 \mathrm{ft})$, it may be calculated that in the worst case ( 3 cycles, $0.3-\mathrm{m}$ double amplitude) the measured stopping distance is in error 
by $-0.37 \mathrm{~m}(-1.2 \mathrm{ft})$. In the more general case ( 2 cycles, $0.15-\mathrm{m}$ double amplitude) the error is only a tenth of this. It would seem appropriate, therefore, to require that the bicycle be moving in a straight line when the brakes are applied in the road test, in order to minimize the side skid. This could be accomplished by painting straight lines, say $0.3 \mathrm{~m} \mathrm{(} 1 \mathrm{ft}$ ) apart, along the length of the test pavement, as guides for the rider.

These errors are primarily of a random nature.

\section{REACTION TIME}

Most laboratories which have carried out the road test under controlled conditions have used preset lever stops to assure that the maximum force applied to the handbrake lever, by the rider, does not exceed the prescribed value. A finite interval of time passes between the instant that the rider first begins to actuate the lever and the instant that the applied force reaches the maximum or prescribed value. Measurements of this interval have been made by at least three investigators. NBS data, obtained with a variety of bicycles and riders, indicate that the interval is approximately $0.11(+0.22,-0.08)$ seconds [13]. Measurements by a manufacturer suggest that the interval is much shorter than this [8]. However, examination of the test method used by this manufacturer reveals that, in reality, only a portion of the interval was measured, namely, that portion during which the brake pads were moved into contact with the wheel rim. Data obtained by another manufacturer suggest that the interval is considerably longer than that indicated by the NBS results [9]. These data must also be considered suspect because they imply that, on the average, the applied force does not reach the maximum value until the bicycle has traveled at least $3.7 \mathrm{~m}$ ( $12 \mathrm{ft}$ ).

An additional delay in achieving full braking action results from the fact that, in general, the two handbrake levers are not applied simultaneously. NBS measurements, made with a variety of bicycles, indicate that the departure from perfect synchronization is approximately 0.04 ( $+0.05,-0.04)$ seconds, taking no heed of whether the front brake or the rear brake is applied first [13]. Measurements by a manufacturer, using a variety of riders, essentially confirm this approximation [9]. Data from another manufacturer imply that the departure from synchronization is only about half this long [12].

If the NBS results given in the two preceding paragraphs are combined it is seen that there is a total delay of $0.15(+0.27,-0.12)$ seconds between the instant that the rider begins actuation of the first brake lever and the instant at which full braking action is achieved. For want of a better name this total delay will be called the "reaction time". 
These results indicate that if a variety of riders test a variety of bicycles their average reaction time is 0.15 seconds. But if two randomly selected riders test randomly selected bicycles their reaction times may differ by as much as 0.39 seconds. The question that must be answered is, "What is the error introduced due to the reaction time of a given rider on a given bicycle?". This question cannot be answered because the "correct" reaction time is undefined. However, the question can be posed in a different way, i.e., "What reaction time properly characterizes the capabilities of a bicycle's braking system?" Considering the purpose of the road test it appears reasonable to use the average reaction time. Therefore, it is postulated that the correct measure of a bicycle's braking capabilities is achieved with a reaction time of 0.15 seconds.

During the interval represented by the reaction time the deceleration of the bicycle rises from zero to its maximum value. For the purpose of this analysis it will be approximated that the deceleration rises linearly with time. It is further assumed that the level of deceleration achieved at the end of the interval is thereafter maintained constant until the bicycle comes to a stop. With these assumptions it may be shown that the stopping distance is given by

$$
\bar{s}=\frac{v_{0}^{2}}{2 \bar{a}}+\frac{v_{0} t_{1}}{2}-\frac{\bar{a} t_{1}{ }^{2}}{24}
$$

where $\bar{s}$ is the stopping distance, $v_{0}$ is the initial speed, $\bar{a}$ is the maximum deceleration, and $t$ is the reaction time. In order for the bicycle to stop in $4.57 \mathrm{~m}$ ( $15.0 \mathrm{ft}$ ) from an initial speed of $24 \mathrm{~km} / \mathrm{h}$ (15 $\mathrm{mph}$ ), with a reaction time of 0.15 seconds, the maximum deceleration must be not less than $5.52 \mathrm{~m} / \mathrm{s}^{2}\left(18.1 \mathrm{ft} / \mathrm{s}^{2}\right.$ ) or $0.563 \mathrm{~g}$. (This, of course, exceeds the average deceleration rate of $0.5 \mathrm{~g}$ which ignores the existence of a reaction time.)

Consider, now, a bicycle with marginal braking capability $(B=1)$. This is one which stops in exactly $4.57 \mathrm{~m}$ ( $15.0 \mathrm{ft}$ ) with a reaction time of 0.15 seconds. In other words, it has braking capability that provides a maximum deceleration of exactly $0.563 \mathrm{~g}$ under the specified test conditions. In a given test of this bicycle the rider's reaction time, as stated above, will be $0.15(+0.27,-0.12)$ seconds, or anywhere from 0.03 seconds to 0.42 seconds. Using the above equation it may be shown that this range of reaction times corresponds to stopping distances ranging from $4.18 \mathrm{~m}(13.7 \mathrm{ft})$ to $5.46 \mathrm{~m}$ (17.9 ft). Thus, the error band in the observed stopping distance is $-0.39,+0.89 \mathrm{~m}(-1.3,+2.9 \mathrm{ft})$, where the minus and plus signs indicate that the observed stopping distance is less or more, respectively, than the stopping distance which characterizes the bicycle's true braking capabilities. The total variation of stopping distances due to reaction time is $1.28 \mathrm{~m}(4.2 \mathrm{ft})$, which is less than that estimated by ISO $(1.65 \mathrm{~m}, 5.5 \mathrm{ft})$ [5]. 


\section{MEA SUREMENT AND CONTROL OF INITIAL SPEED}

"Bicycles with an equivalent ground speed in excess of $24 \mathrm{~km} / \mathrm{hr}$ (15 mph) (in its highest gear ratio at a pedal crank rate of 60 revolutions per minute) shall stop from an actual test speed of $24 \mathrm{~km} / \mathrm{hr}$ (15 mph) or greater within a distance of $4.57 \mathrm{~m}$ (15 ft)..." [Bicycle Safety Regulation].

\subsection{Measurement}

The accuracy with which the ground speed of the bicycle can be measured, at the start of the road test, has a significant influence on the results of the test since, as shown in Equation (28), the stopping distance is very nearly proportional to the square of the initial speed. In effect, the percentage error in the measured stopping distance is twice the percentage error in the measured speed.

Two basic techniques, with several variations, have been used for measuring the initial speed. Perhaps the most straightforward approach involves the use of a speedometer on the test bicycle. Most commercially available bicycle speedometers are relatively inaccurate, however, and laboratories which use them generally calibrate them beforehand $[10,15]$. While it has been claimed that calibrated speedometers have an accuracy of only \pm 5 percent [5], there does not appear to be any reason why a proper calibration performed at the desired speed ( $24 \mathrm{~km} / \mathrm{h}, 15 \mathrm{mph}$ ) should not be capable of providing \pm 1 percent accuracy.

A similar approach involves the use of a laboratory tachometer. Precision tachometers are available with rated accuracies substantially better than \pm 1 percent [16], and these have been used to assemble accurate speedometers for bicycle-testing purposes [8].

The difficulty with the speedometer technique is that calibration must be repeated for each size of bicycle wheel [9]. Furthermore, the rider is so preoccupied with other matters that he cannot be expected to read the speed carefully an instant before he applies the brakes. This factor is estimated to degrade the accuracy of this speed-measuring technique to no better than about \pm 3 percent [ 3 .

In order to reduce the reading errors, and to avoid the need for recalibration with each size of bicycle wheel, several manufacturers have experimented with pacer bicycles $[9,12,17]$. In this approach, which was at one time specified by ISO [18], the rider of the test bicycle follows a second (pacer) bicycle which is equipped with a calibrated speedometer. The rider of the pacer bicycle, being unconcerned with braking, can concentrate on reading the speedometer carefully. The rider of the test bicycle need only keep pace with the pacer bicycle until he applies the brakes. However, inasmuch as the speed of the test bicycle 
may differ from that of the pacer bicycle, it is unlikely that speed measurements with accuracies better than \pm 3 percent can thereby be attained consistently [9].

An error of \pm 3 percent in speed measurement produces an error of approximately \pm 6 percent in the measured stopping distance, or \pm 0.27 $\mathrm{m}( \pm 0.9 \mathrm{ft})$ over a $4.57 \mathrm{-m}(15.0-\mathrm{ft})$ course. This error will be considered random since it consists, primarily, of inaccuracies in reading the speedometer rather than inaccuracies in calibrating it.

In an effort to achieve better accuracy several testing groups have used electronic timing traps. In the common version of this technique two tape switches are set out on the pavement, perpendicular to the bicycle path and at a known distance apart $[9,11,12,19]$. The bicycle wheels operate the switches as the bicycle passes over them and the interval between switch operations is measured electronically. The speed is calculated from the time interval and the distance between the switches. A variation of this technique uses a single tape switch which is operated, in succession, by the two bicycle wheels as they pass over it [13]. In this case the required length measurement is of the bicycle wheel base rather than the distance between tape switches. The advantage of this approach is that it does not require that the tape switch be perfectly normal to the bicycle path.

Regardless of whether one tape switch or two are used, the accuracy of the speed measurement depends on the accuracies of the length and time measurements. On this basis it has been asserted that the error in speed measurement is less than \pm 1 percent $[3,9,12]$ and this assertion appears to be justifiable, ISO claims of \pm 2 percent $[5,6]$ notwithstanding. This $t 1$ percent error in speed measurement corresponds to a random error of $\pm 0.09 \mathrm{~m}( \pm 0.3 \mathrm{ft})$ in stopping distance.

While the electronic timing trap does provide an accurate measurement of the average bicycle speed while it traverses the trap it does not, in fact, measure the speed at the instant of brake actuation. Usually, the rider allows the bicycle to travel a short distance beyond the trap before actuating the brakes in order to avoid the possibility of braking before emerging from the trap. In traveling this short distance the bicycle experiences a reduction in speed due to wind resistance and to rolling friction in the wheel bearings and at the tire/pavement interfaces. To reduce the effects of this speed reduction ISO has recommended that a test be declared invalid if the distance between the last timing strip and the center of the rear wheel at the commencement of braking exceeds $2 \mathrm{~m}$ (6.6 ft) $[5,6]$.

This appears to be a reasonable requirement since NBS riders have typically actuated the brakes within 1.5 to $2 \mathrm{~m}$ ( 4.9 to $6.6 \mathrm{ft}$ ) after passing the trap. One manufacturer, however, reports distances of 1.9 to $2.5 \mathrm{~m}$ (6.1 to $8.3 \mathrm{ft})[9]$. 
In an effort to evaluate the speed reduction that occurs over this distance, the deceleration of a freewheeling (coasting) bicycle was measured with the aid of a special dynamometer. The results showed a fairly constant deceleration of $0.37 \mathrm{~m} / \mathrm{s}^{2}\left(1.2 \mathrm{ft} / \mathrm{s}^{2}\right)$ [9]. This value seems high, however, since it implies a freewheeling stopping distance of only $60 \mathrm{~m}$ (200 ft) from an initial speed of $24 \mathrm{~km} / \mathrm{h}$ ( $15 \mathrm{mph}$ ). It is speculated that the dynamometer itself may have been responsible for part of the observed braking action.

NBS calculations of wind resistance and rolling friction show that for a typical bicycle and rider the freewheeling deceleration is approximately $0.24 \mathrm{~m} / \mathrm{s}^{2}\left(0.80 \mathrm{ft} / \mathrm{s}^{2}\right)$ at a speed of $24 \mathrm{~km} / \mathrm{h}$ (15 mph), and that the average deceleration, in coming to a stop from this speed, is approximately $0.13 \mathrm{~m} / \mathrm{s}^{2}\left(0.42 \mathrm{ft} / \mathrm{s}^{2}\right)$. This implies a freewheeling stopping distance of approximately $170 \mathrm{~m}$ (560 ft). These calculations were roughly confirmed by two tests with a single bicycle and rider which showed an average freewheeling stopping distance of $129 \mathrm{~m}$ (422 ft).

Assume that the distance traveled, between the timing trap and brake actuation, is $1.75 \pm 0.25 \mathrm{~m}(5.7 \pm 0.8 \mathrm{ft})$ for a valid test. Then, with an initial speed of $\overline{2} 4 \mathrm{~km} / \mathrm{h}(15 \mathrm{mph})$ and a freewheeling deceleration of, say, $0.3 \mathrm{~m} / \mathrm{s}^{2}\left(1 \mathrm{ft} / \mathrm{s}^{2}\right)$, the speed reduction over this distance is $0.08 \pm 0.01 \mathrm{~m} / \mathrm{s}(0.3 \pm 0.03 \mathrm{ft} / \mathrm{s})$. For a nominal stopping distance of $4.57 \mathrm{~m}$ ( $15.0 \mathrm{ft})$ this speed reduction produces an error of approximately $-0.11 \pm 0.01 \mathrm{~m}(-0.4 \pm 0.03 \mathrm{ft})$, where the minus sign indicates that the measured stopping distance is less than the true stopping distance corresponding to the measured speed. This error is primarily of a systematic nature although it contains random components as well.

\subsection{Control}

The Bicycle Safety Regulation calls for the bicycle to be traveling at a specific speed at the initiation of braking in the road test. This imposes an almost impossible burden on the rider aside from the aforementioned difficulties in measuring this speed. It appears more reasonable, therefore, to permit the initial speed to fall within a range of values. However, if the range were set at, say, $t^{5}$ percent of the specified speed, this would introduce variations of $\pm \overline{1} 0$ percent in the stopping distance an undesirable situation. A more acceptable approach would be to permit the initial speed to fall within a range of values and to correct the observed stopping distance to that which would probably have been observed had the initial speed equaled the specified value.

The correction formula is, simply,

$$
\bar{s}_{c}=\bar{s}_{m}\left(\frac{v_{\text {os }}}{v_{\text {om }}}\right)^{2}
$$


where $\bar{s}_{c}$ is the corrected stopping distance, $\bar{s}_{m}$ is the measured stopping distance, $v_{o s}$ is the specified initial speed and $v_{\text {om }}$ is the measured initial speed. While this correction is quite accurate for small deviations in speed, it is not exact since it ignores the effects of the rider's reaction time (see Equation (28)). Therefore, it should not be used to correct for initial speeds which deviate substantially from the specified initial speed. On this basis it has been proposed [12] that tests be declared invalid if the measured initial speed deviates from the specified value by more than $1.5 \mathrm{~km} / \mathrm{h}(0.9 \mathrm{mph})$, and ISO has adopted this proposal $[5,6]$.

\section{EFFECTS OF PAVEMENT SURFACE}

"The bicycle shall be ridden over a dry, clean, ... paved test course..." [Bicycle Safety Regulation].

If one or both wheels of the bicycle skid during the road test the stopping distance is affected by the coefficient of friction between the tires and the pavement. The Bicycle Safety Regulation requires that the pavement be dry and clean but this description is not adequate to define $\mu$. One manufacturer reports that typical values of $\mu$ range from 0.54 to 0.95 [9] but there is evidence that values outside this range are not uncommon. Handbook values for dry macadam and dry asphalt range from 0.67 to $0.71[20,21]$ but individual measurements as high as 1.22 have been reported [13]. Typical values of $\mu$ for smooth concrete surfaces and cement floors range from 0.50 to $0.55[1,10,13]$ but a value of 0.42 has also been reported [3]. Painting concrete and asphalt often lowers the coefficient of friction but special coatings can double it to as high as 1.2 [22].

If a single bicycle is tested on two different pavements, under otherwise identical conditions, different stopping distances will probably be observed. But which one is correct? This question cannot be answered until a specific pavement surface or a specific coefficient of friction is established as the test requirement. In the absence of such a specification the requirement for motorcycle braking tests [7] will be used as a guide and, on this basis, it is postulated that the correct measure of a bicycle's braking capability is achieved on a pavement offering a coefficient of friction of 0.75 . Marginal braking capability $(B=1)$, therefore, corresponds to a stopping distance of exactly 4.57 $\mathrm{m}(15.0 \mathrm{ft})$ under the specified test conditions with $\mu=0.75$. With a rider reaction time of 0.15 seconds, as established above, this braking capability requires a maximum deceleration of $0.563 \mathrm{~g}$.

The effect of $\mu$ on the maximum deceleration of the typical bicycle (Table 1 ) is shown in Figure 4 for braking capabilities of 0.50 (poor), 1.00 (marginal), 1.25 (good) and 1.50 (excessive). The relationships 
plotted in the figure were calculated from Equations (1), (2), (15), (20), (24), (25) and (27). (It is, perhaps, worth noting here that comprehensive experimental data showing the effects of $\mu$ on braking performance are not available simply because no laboratory has a number of suitable test courses with different pavement surfaces offering a wide range of friction coefficients. Comparing results from different laboratories in order to ascertain the effects of $\mu$ is unrewarding since the effects are obscured by other differences in their respective measurement systems.)

At low values of $\mu$ both wheels of the bicycle lock and skid and the relation between maximum deceleration and friction coefficient is given by 1 ine $O A B C D$ regardless of the braking capability. At higher values of $\mu$ and poor-to-good braking capability the front wheel rolls while the rear wheel skids (curves $A E, B G$ and $C H$ ). With excessive braking capability pitchover occurs (point D) with both wheels locked and skidding. At very high values of $\mu$ and poor braking capability both wheels of the bicycle roll (1ine EF).

The maximum deceleration values can be converted to stopping distances through the use of Equation (28). This is shown in Figure 5 for the typical bicycle with marginal braking capability. It is seen that with a friction coefficient of 0.75 the stopping distance is exactly $4.57 \mathrm{~m}$ (15.0 ft); higher coefficients produce shorter stopping distances and lower coefficients produce longer stopping distances. The sharp break in the curve, which occurs at $\mu=0.547$, represents the changeover from both wheels locked and skidding (on the left) to rear wheel locked and front wheel rolling (on the right).

Clearly, without specifying $\mu$, the stopping distances measured on various pavements would vary widely, even for a single bicycle. In Figure 5 it is seen that, for the typical bicycle with marginal braking capability, the measured stopping distance could range from 4.39 to $5.96 \mathrm{~m}$ (14.4 to $19.6 \mathrm{ft})$ over the span of observed friction coefficients $(0.42$ to 1.22). This represents an error band of $+1.39,-0.18 \mathrm{~m}(+4.6,-0.6 \mathrm{ft})$ where the plus sign indicates that the observed stopping distance exceeds the correct one. This is a rather large error band.

Several approaches to reducing this error band might be considered. The obvious approach would be to specify a particular value of $\mu$ which the test pavement should offer. This approach presents difficulties, however. The friction coefficient is not an easy property to measure reproducibly. ASTM Method E274 [23] is the method used for characterizing pavements for motorcycle testing [7], and it is probably the most reproducible method available, but it requires complex and expensive equipment.

A second approach, following an ISO recommendation $[5,6]$, would be to simply require that the friction coefficient be high enough to prevent the front wheel from locking. In the example shown in Figure 5 , this would limit $\mu$ to values between 0.547 and 1.22 , which corresponds 
to stopping distances from 4.39 to $4.69 \mathrm{~m}$ (14.4 to $15.4 \mathrm{ft})$. This represents an error band of $+0.12,-0.18 \mathrm{~m}$ ( $+0.4,-0.6 \mathrm{ft})$ which is a substantial improvement over the error band cited above. The problem with this approach is that it might encourage the use of test pavements with unusually high friction coefficients, which might introduce a pitchover hazard for bicycles with powerful braking capabilities.

This problem could probably be overcome by requiring that the pavement, in addition to being dry and clean, also be flat and free from coarse or protruding aggregate. This would probably limit the maximum value of $\mu$ to no higher than about 1.0. Thus, for $\mu$ ranging from 0.547 to 1.0 , Figure 5 shows stopping distances ranging from 4.46 to $4.69 \mathrm{~m}$ (14.6 to $15.4 \mathrm{ft})$. This represents an error band of $\pm 0.12 \mathrm{~m} \mathrm{(} \pm 0.4 \mathrm{ft}$ ), which is reasonable.

The errors in stopping distance, due to pavements which offer friction coefficients other than 0.75 , are systematic errors.

Further discussion of the tire/pavement friction coefficient is given in Section 14.2 .

\section{UNCERTAINTIES IN THE APPLIED LEVER FORCES}

"A spring scale or other suitable device [shall be used] for measuring the specified forces on the handbrake levers...

"The stopping force applied to the hand lever at a point no closer than $25 \mathrm{~mm}$ (1.0 in) from the open end shall not exceed $178 \mathrm{~N}$ (40 1bf)" [Bicycle Safety Regulation].

It is clear that the application of a force to the handbrake lever, which is less than the prescribed maximum, would reduce the braking performance of the bicycle provided that one or both wheels are rolling. Therefore, except when operating near the pitchover condition, it is axiomatic that the maximum prescribed force is also the correct force to be applied.

\subsection{Kinetic Analysis}

The effect of the applied lever forces, on the maximum deceleration of the typical bicycle (Table 1) is shown in Figures 6 and 7 for several braking capabilities. Figure 6 is for a tire/pavement friction coefficient of 0.75 and Figure 7 is for a coefficient of 0.50 . The curves were calculated from Equations (1), (2), (15), (20), (24), (25) and (27).

With low values of applied lever force, both wheels of the bicycle roll. This condition applies to lines $O A, O C$ and $O E$ in Figure 6 , and 
to lines $O A, O D$ and $O F$ in Figure 7. With higher values of applied lever force the rear wheel locks and skids while the front wheel continues to roll. With $\mu=0.50$, still higher values of applied lever force cause both wheels of the bicycle to lock and skid, resulting in saturation braking, as shown by 1 ine BEGC in Figure 7. Note that, in this case, the maximum deceleration ratio, $\bar{a} / g$, is numerically equal to the friction coefficient (cf Equation (25)). With $\mu=0.75$ (Figure 6), pitchover occurs (points $B$ and $D$ ) before the saturation condition is reached.

\subsection{Error Analysis}

Errors in the applied force can result from three principal sources. The measurement of the force may be inaccurate, the force may be applied at the wrong point, or it may be applied in the wrong direction.

Most testing groups have used preset lever stops to assure that the applied forces do not exceed the prescribed 1 imit $[8,9,10,12,13]$. In this technique the stops are adjusted to prevent further travel of the levers when the prescribed force levels are reached. The prescribed forces are measured with spring dynamometers of one kind or another.

In principle, at least, spring dynamometers can be calibrated to better than one-percent accuracy using dead weights. In practice, however, most of these devices lack a high degree of repeatability. Some degree of error is also introduced by the fact that the thickness of a wheel rim is not uniform around the periphery of the wheel. Thus, if the lever stop is preset with the wheel in one position, the lever force may differ at other wheel positions [9]. Also, erratic friction between the cable and the casing of the brake system results in variations of the applied force using a preset lever stop [10]. As a consequence of the above factors it has been estimated that the magnitudes of the applied lever forces may vary from the prescribed force level by up to \pm 5 percent $[9,12]$. This appears to be a fair estimate. Such variations lead to random errors in stopping distance.

While it is important that the magnitude of the force applied to the handbrake lever be correct, it is more important that the caliper brake pads apply the proper forces to the wheel rims. Thus, if the lever force is applied at the wrong point on the lever or in the wrong direction, the effect will be the same as if the wrong lever force were applied. When setting the lever stops the spring dynamometer should be attached to the lever at precisely $25 \mathrm{~mm}$ (1.0 in) from the tip. For most bicycles the lever arm from this point to the lever pivot point is approximately $100 \mathrm{~mm}$ ( $4 \mathrm{in})$. Since levers are curved it is difficult to attach the spring dynamometer at the precise point and errors of $+2 \mathrm{~mm}$ ( $\pm 0.08 \mathrm{in})$ appear to be reasonable. This represents an error of $+\overline{2}$ percent in the 1 ever arm and, in effect, a systematic error of +2 percent in the applied force. One manufacturer has attributed much larger errors to the difficulty in applying the force at the specified point on the lever [9]. 
The Bicycle Safety Regulation does not specify the direction in which the force should be applied. For maximum braking, of course, the force vector should lie in the plane in which the lever moves and should be perpendicular to a line from the pivot point to the application point when the lever is against the preset stop. This is a difficult requirement and it is estimated that deviations of up to $\pm 15^{\circ}$ in the direction of the applied force could be encountered. The effective applied force is proportional to the cosine of the deviation angle so systematic errors up to -3 percent could result.

Summing up, the total error in the force applied to the handbrake lever is $+7,-10$ percent. Stated differently, when pulling the handbrake lever against its preset lever stop the actual force applied may range from 160 to $190 \mathrm{~N}$ (36 to $43 \mathrm{lbf}$ ). The effect of this variability on the maximum deceleration of the typical bicycle with marginal braking capability is given by 1 ine $\mathrm{CD}$ in Figure 6 . These deceleration values may be converted to stopping distances through the use of Equation (28) with a rider reaction time of 0.15 seconds. The following results are obtained:

$\frac{\text { Applied lever force }}{\mathrm{N}}$

178

190 $\frac{\text { Stopping distance }}{\mathrm{m}}$

4.79

4.57

4.43
$(15.7)$

$(15.0)$

$(14.5)$

These data show that the variability of the applied lever force results in an error band on the stopping distance of t0.22, $-0.14 \mathrm{~m}(+0.7,-0.5$ $\mathrm{ft}$ ), where the plus sign indicates that the observed stopping distance exceeds the correct one. The systematic part of this error band is approximately $+0.11,-0.03 \mathrm{~m}(+0.4,-0.1 \mathrm{ft})$ and the random part is approximately $\pm 0.11 \mathrm{~m}( \pm 0.4 \mathrm{ft})$.

\section{MASS (WEIGHT) EFFECTS}

\subsection{Locating the Center of Gravity}

"The bicycle shall be ... stopped by the rider while remaining in a normal riding position throughout the stop..." [Bicycle Safety Regulation].

Since the force of gravity which acts on the rider, $W$, is the product of the rider's mass, $M_{r}$, and the local acceleration of gravity, $g$, Equations (15) and (20) can be used to show the effect of the rider's mass on the 
maximum deceleration which is obtained under the specified test conditions.* However, when the rear wheel of the bicycle locks and skids whilc the front wheel rolls, the calculation (Equation (20)) is not straightforward a priori since changing the rider's mass also changes the location of the center of gravity $(l, H)$ of the bicycle/rider system.

Very little data are available on the manner in which the horizontal location, $\ell$, of the cg changes with rider mass, and even less on the manner in which the vertical location, $H$, is affected. Intuitively, it would seem that increasing the mass of the rider would move the $\mathrm{cg}$ of the system both upward and rearward, and that the relative effect would be greater on 1 ightweight bicycles than on heavy ones. Yet, the following NBS measurements, made with two bicycles, fail to confirm these trends.

\begin{tabular}{|c|c|c|c|c|}
\hline $\mathrm{Bic}$ & mass & & mass & $2 / L$ \\
\hline & $\overline{(1 b)}$ & $\overline{\mathrm{kg}}$ & (1b) & \\
\hline 6.8 & (15) & 0 & (0) & 0.57 \\
\hline & & 77 & $(170)$ & .50 \\
\hline & & 93 & (204) & .55 \\
\hline & & 98 & (215) & .54 \\
\hline 21 & $(46)$ & 0 & (0) & .42 \\
\hline & & 62 & $(136)$ & .56 \\
\hline & & 77 & $(170)$ & .53 \\
\hline & & 91 & $(200)$ & .51 \\
\hline
\end{tabular}

It is concluded that the differences in the mass distributions of the riders, due to differences in height, physique, attitude, seat height, etc., serve to mask the anticipated trends due to changes of rider mass alone. On the other hand, these data show that the variations of $\mathrm{l} / \mathrm{L}$ are not large. Since some test results are available [10] which show that changing the seat height, with a given rider, affects stopping distance only minimally, the possibility suggests itself that the variations of the $\mathrm{cg}$ location with rider mass may not be an important consideration.

In order to check this hypothesis the data in Tables 2 and 3 were used. These represent the only data which were found showing the effects of rider mass on both $\ell / L$ and $H / L$ for specific bicycles [15]. The maximum decelerations for these two bicycles were calculated with Equations (1), (2) and (20), normalizing the braking capabilities to the marginal condition ( $0.563 \mathrm{~g}$ with a $68.1 \mathrm{-kg}$ rider). In one set of calculations the cg location was allowed to vary with rider mass as specified in Tables

When both wheels of the bicycle lock and skid the deceleration is independent of the rider's mass (cf Equation (25)). 
2 and 3 ; in a second set of calculations the cg location was assumed to remain fixed regardless of rider mass. The results are as follows:

\begin{tabular}{|c|c|c|c|c|}
\hline \multirow[b]{2}{*}{ Bicycle } & \multirow{2}{*}{\multicolumn{2}{|c|}{ Rider mass, $M_{2}$}} & \multicolumn{2}{|c|}{ Maximum deceleration, $\bar{a} / g$} \\
\hline & & & varying $\mathrm{cg}$ & fixed $\mathrm{cg}$ \\
\hline High rise & $\begin{array}{l}45.4 \\
68.1 \\
86.2\end{array}$ & $\begin{array}{l}(100) \\
(150) \\
(190)\end{array}$ & $\begin{array}{r}0.653 \\
.563 \\
.519\end{array}$ & $\begin{array}{r}0.645 \\
.563 \\
.523\end{array}$ \\
\hline Conventional & $\begin{array}{l}45.4 \\
68.1 \\
86.2\end{array}$ & $\begin{array}{l}(100) \\
(150) \\
(190)\end{array}$ & $\begin{array}{l}.649 \\
.563 \\
.525\end{array}$ & $\begin{array}{l}.653 \\
.563 \\
.519\end{array}$ \\
\hline
\end{tabular}

These results show that the effect of the changes in the cg location on maximum deceleration are small indeed, amounting to less than 2 percent

in the most extreme case. Therefore, it appears that for the purpose of calculating the effects of rider mass on stopping distance, the use of a fixed cg will yield reasonably accurate results. It remains only to select typical values of $\ell / L$ and $H / L$ for these calculations.

One manufacturer [9] has suggested that for most bicycles

$$
\ell / \mathrm{L} \approx 2 / 3 \text { and } \mathrm{H} / \mathrm{L} \approx 1 \text {. }
$$

Comparison of these values with the NBS data cited earlier, and with the data in Tables 2 and 3, suggest that lower values would be more typical, however. On this basis the values

$$
\ell / L=0.60 \text { and } H / L=0.85
$$

were selected for the typical bicycle characteristics which were set forth in Table 1.

$$
\begin{aligned}
& \text { 10.2 Effect of Rider Mass on Maximum Deceleration } \\
& \text { "A bicycle equipped with only handbrakes shall be } \\
& \text { tested for stopping distance by a rider of at least } \\
& 68.1 \mathrm{~kg}(150 \text { 1b) weight..." [Bicycle Safety Regula- } \\
& \text { tion]. }
\end{aligned}
$$

The effect of rider mass on the maximum deceleration of the typical bicycle (Table 1), with several braking capabilities, is shown in Figures 8 and 9. Figure 8 is for a tire/pavement friction coefficient of 0.75 and Figure 9 is for a coefficient of 0.50 . Equations (1), (2), (15), $(20),(24),(25)$ and (27) were used for these calculations. 
For a friction coefficient of 0.75 , Figure 8 shows that with marginal or excessive braking capability (curves $A B$ and $C D$ ) changing the rider's mass does not change the mode of braking; the rear wheel skids while the front wheel rolls, over the entire range of rider masses considered. These two curves culminate in pitchover (points $C$ and A) for underweight (i.e., less than $68.1-\mathrm{kg}$ ) riders. With poor braking capability the braking changes to both wheels rolling for heavy riders (curve FG).

For a friction coefficient of 0.50, Figure 9 shows that front-wheel locking and saturation braking ( 1 ine $A C B$ ) is reached before pitchover can occur, and the bicycle with excessive braking capability operates in this mode over the entire range of rider masses considered.

\title{
10.3 Effect of Rider Mass on Stopping Distance
}

\begin{abstract}
"A bicycle...shall have a stopping distance of no greater than $4.57 \mathrm{~m}$ (15 ft) from the actual test speed...

"The stopping distances specified are based on a rider weight of $68.1 \mathrm{~kg}(150 \mathrm{lb})$ and greater stol'ping distances are allowable for heavier riders at the rate of $0.30 \mathrm{~m}$ per $4.5 \mathrm{~kg}(1.0 \mathrm{ft} \text { per } 101 \mathrm{~b})^{\prime \prime}$ [Bicycle Safety Regulation].
\end{abstract}

The maximum deceleration data shown in Figure 8 can be converted to stopping distances through the use of Equation (28) and a rider reaction time of 0.15 seconds. The effect of rider mass on stopping distance is shown by curve OA in Figure 10 for the typical bicycle with marginal braking capability. Point 0 in the figure represents the marginal condition, a stopping distance of $4.57 \mathrm{~m}(15.0 \mathrm{ft})$ with a $68.1-\mathrm{kg}$ (150 $-1 \mathrm{~b})$ rider. Line OC represents the allowable stopping distance permitted by the Bicycle Safety Regulation for overweight riders, at the rate of $0.30 \mathrm{~m}$ per $4.5 \mathrm{~kg}$ (1.0 ft per $10 \mathrm{lb})$.

The allowance for overweight riders clearly exceeds the effect of overweight riders. The error--the difference between the allowable stopping distance and the actual stopping distance--favors the overweight rider. The greater the mass of the rider, the greater is his advantage over the 68.1-kg (150-1b) rider. A bicycle with inadequate braking capability, which could not pass the road test with a $68.1-\mathrm{kg}(150-1 \mathrm{~b})$ rider, could easily do so with a rider of sufficient mass.

The magnitude of the error increases indefinitely with increasing . rider mass, ranging, for example, from zero for a $68.1-\mathrm{kg}$ (150-1b) rider to $-2.50 \mathrm{~m}(-8.2 \mathrm{ft})$ for a $120-\mathrm{kg}(265-1 \mathrm{~b})$ rider. This error is a systematic one, and the minus sign indicates that the braking performance of the bicycle, as indicated by the allowable stopping distance, is less than that required for marginally acceptable performance. One approach toward reducing the size of this error, which has been proposed by ISO [6], 
would limit the combined weight of the rider and instrumentation to a maximum of $85 \mathrm{~kg}(187 \mathrm{lb})$. Ignoring the weight of the instrumentation "for the moment, Figure 10 shows that this limitation reduces the maximum error to $-0.76 \mathrm{~m}(-2.5 \mathrm{ft})$. This is still a sizeable error.

A better approach might be to change the allowable correction from $0.3 \mathrm{~m} / 4.5 \mathrm{~kg}(1 \mathrm{ft} / 10 \mathrm{lb}$ ) to that which would make the line OC, in Figure 10, tangent to the stopping distance curve at point 0 . The slope of the stopping distance curve may be found from Equations (20) and (28) by differentiation, and it is found, in this manner, that a suitable correction factor would be $0.024 \mathrm{~m} / \mathrm{kg}(0.035 \mathrm{ft} / 1 \mathrm{~b}) *$ which is equivalent to a rate of approximately $0.11 \mathrm{~m}$ per $4.5 \mathrm{~kg}(0.35 \mathrm{ft}$ per $10 \mathrm{lb})$. With this allowance the error in stopping distance, with a $120-\mathrm{kg}$ (265-1b) rider would be only $-0.31 \mathrm{~m}(-1.0 \mathrm{ft})$.

\subsection{Instrumentation Mass}

Regarding the mass of the instrumentation which must be carried by the bicycle in order to perform the road test, it has been suggested that this mass be treated in the same manner as added rider mass for the purpose of correcting the measured stopping distance [6]. This is a reasonable suggestion provided that the instrumentation is located such that it does not significantly change the location of the center of gravity of the bicycle/rider system. This is the practice which has been advocated by one manufacturer [9]. If the instrumentation is located principally over the front wheel then the $\mathrm{cg}$ is moved forward and the correction factor proposed above would not be sufficient to account for the effect of the instrumentation mass. For example, adding $10 \mathrm{~kg}$ (22 1b) over the front wheel of the typical bicycle would raise the stopping distance from $4.57 \mathrm{~m}$ ( $15.0 \mathrm{ft}$ ) to $5.04 \mathrm{~m}$ (16.5 ft), an increase of 0.47 $\mathrm{m}(1.5 \mathrm{ft})$, while the correction factor proposed above would only allow for an additional $0.24 \mathrm{~m}(0.8 \mathrm{ft})$. On the other hand, adding the $10 \mathrm{~kg}$ (22 $\mathrm{lb}$ ) over the rear wheel of this bicycle would reduce the stopping distance to $4.43 \mathrm{~m}$ (14.5 ft) without any correction factor having been applied!

In order to avoid the variabilities in stopping distance that can result from placement of the instrumentation and from rider mass, the practice used for thoroughbred racing and for motorcycle testing [7] could serve as a guide. As applied to bicycle testing, this approach would specify a fixed payload of, say, $91 \mathrm{~kg}$ (200 lb), consisting of

*This appears to be a conservative value. Calculations show that the corresponding factor for the high rise bicycle (Table 2) is 0.019 $\mathrm{m} / \mathrm{kg}(0.028 \mathrm{ft} / \mathrm{lb})$, and for the conventional bicycle (Table 3 ) it is $0.021 \mathrm{~m} / \mathrm{kg}(0.031 \mathrm{ft} / 1 \mathrm{~b})$. 
the rider, the instrumentation and added mass, with the instrumentation and the added mass distributed fore and aft so as not to cause a major dislocation of the center of gravity of the bicycle/rider system. With this approach, all bicycles would be tested with the same total payload and a correction for overweight riders would be obviated.

\subsection{Pitchover}

The final topic to be discussed under the subject of mass effects is pitchover. This topic has generated considerable controversy. One manufacturer has stated that the 4.57 -m (15.0-ft) stopping distance requirement of the performance test presents a serious pitchover hazard [24]. A second manufacturer has claimed that its test riders would refuse to test if the full $178 \mathrm{~N}$ (40 lbf) were required to be applied to the hand brake levers [25]. An independent laboratory, however, which conducted over two hundred braking tests in which the applied lever forces were not limited to $178 \mathrm{~N}$ (40 $1 \mathrm{bf})$, reported that no instance of pitchover (or even lifting of the rear wheel) occurred when the rider remained seated throughout the braking period [15]. Several pitchovers occurred in tests conducted at NBS [13] but only on a test course which offerred an excessively high tire/pavement coefficient of friction ( $\mu=1.22$ ).

The threshold decelerations for pitchover, calculated from Equations (24) and (27), are tabulated below for the typical bicycle (Table 1 ), the high rise bicycle (Table 2) and the conventional bicycle (Table 3 ). The latter bicycles are included in this tabulation in order to examine the effects on pitchover of the change in cg location with rider mass.

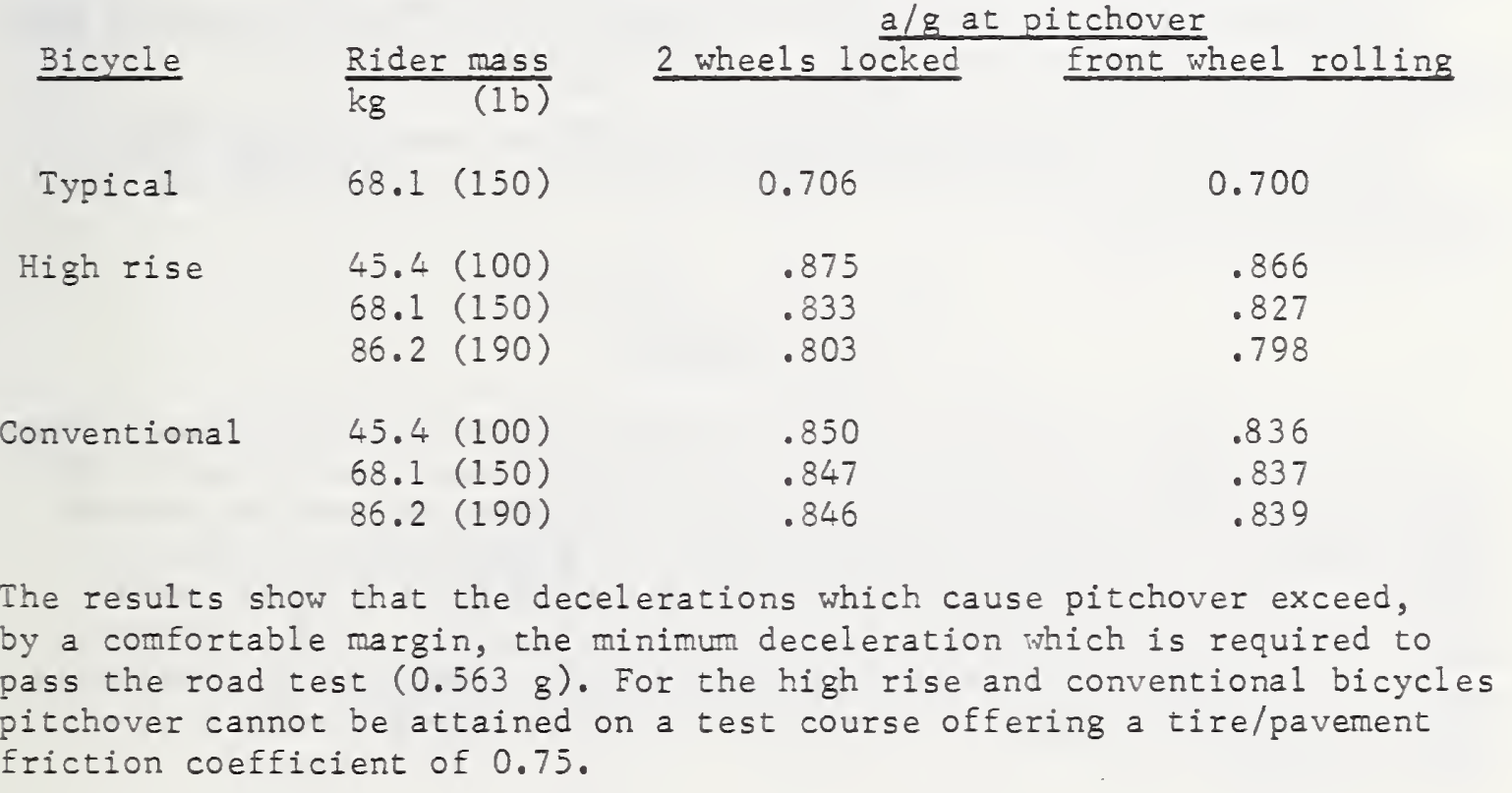




\section{EFFECT OF INCLINED ROADWAY}

"The bicycle shall be ridden over a ... level paved test course..." [Bicycle Safety Regulation].

Although the Regulation requires that the test course be level, it can hardly be expected that many cesting groups will build test courses specifically for this purpose. The ISO requires only that the test surface be "substantially" level [6]. NBS measurements suggest that inclinations up to about $1 / 4$ degrees may be undetectable to the naked eye without a comparison reference.

If the test surface is inclined then the deceleration is

$$
\frac{a}{g}=\frac{f_{r}+f_{f}}{W_{b}+W_{r}}+\sin B
$$

which, of course, reduces to Equation (14) when $\beta$ is zero. The angle of inclination, $\beta$, is considered positive for an upward incline. This equation shows that a bicycle which could achieve the minimum required deceleration rate of $0.563 \mathrm{~g}$ on a level surface would attain a deceleration of $0.570 \mathrm{~g}$ on an upward incline of 0.25 degrees, and a deceleration of $0.556 \mathrm{~g}$ on a downward incline of 0.25 degrees. Using Equation (28) and a rider reaction time of 0.15 seconds it is found that these deceleration values correspond to stopping distances of 4.52 and $4.62 \mathrm{~m}$ (14.8 and $15.2 \mathrm{ft})$, respectively, or an error band of $\pm 0.05 \mathrm{~m}$ ( $\pm 0.2 \mathrm{ft}$ ).

With a one-percent grade ( $\sin \beta=0.01, \beta=0.57 \mathrm{deg}$ ) the error band is $\pm 0.08 \mathrm{~m}( \pm 0.3 \mathrm{ft})$.

These errors, which are systematic, could be rendered negligible by conducting the road tests in both directions on the test course and averaging the results.

\section{WIND EFFECTS}

The procedure for conducting performance tests on motorcycle braking systems specifies that the tests be carried out under conditions of zero wind velocity [7]. While the Bicycle Safety Regulation does not address this problem it is obvious that, in order to minimize the variability of test results, it is desirable that these tests also be carried out under conditions of zero wind velocity. Unfortunately, such conditions are not consistently attainable on outdoor test courses and, recognizing this, the ISO has specified that the wind speed shall not exceed $3 \mathrm{~m} / \mathrm{s}$ $(6.7 \mathrm{mph})[6]$. 
Wind resistance is, in essence, a force which, depending upon its direction, may aid or retard the deceleration of the test bicycle. If the effects of wind resistance are included, the deceleration of the bicycle may be expressed as (cf Equation (14))

$$
\frac{a}{g}=\frac{f_{r}+f_{f}+F_{w}}{W_{b}+W_{r}}
$$

where, following the customary approach,

$$
F_{W}=k C \rho \frac{\left(v-v_{W}\right)^{2}}{2} A
$$

in which $C$ is the aerodynamic drag coefficient,

$$
\begin{aligned}
& \rho \quad \text { is the mass density of air, } \\
& v \quad \text { is the bicycle speed, } \\
& v_{W} \quad \text { is the component of wind velocity in the direction of bicycle } \\
& \text { motion, } \\
& \text { A is the projected area of the bicycle/rider system normal } \\
& \text { to the direction of motion, and } \\
& k=\left\{\begin{array}{l}
+1 \text { if } v-v_{W}>0 \\
-1 \text { if } v-v_{W}<0
\end{array}\right.
\end{aligned}
$$

Since, in the road test, the bicycle speed varies from its initial value to zero, $F_{W}$ also changes continuously. Thus, the deceleration is not constant and the exact calculation of stopping distance, while entirely feasible, is exceedingly tedious. As a simplifying approximation, therefore, it is assumed that $F_{W}$ is given with sufficient accuracy by its average value, $\bar{F}_{W}$. That is,

$$
\bar{F}_{W}=\frac{1}{v_{0}} \int_{0}^{v_{0}} F_{w} d v,
$$

which leads to

$$
\begin{array}{ll}
\overline{\mathrm{F}}_{\mathrm{W}}=\frac{1}{2} \operatorname{c\rho A}\left(\frac{\mathrm{v}_{0}^{2}}{3}-\mathrm{v}_{\mathrm{O}} \mathrm{v}_{\mathrm{W}}+\mathrm{v}_{\mathrm{W}}^{2}\right), & \mathrm{v}_{\mathrm{W}} \leq 0, \\
\overline{\mathrm{F}}_{\mathrm{W}}=\frac{\operatorname{C\rho A}}{6 \mathrm{v}_{0}}\left[\left(\mathrm{v}_{\mathrm{O}}-\mathrm{v}_{\mathrm{W}}\right)^{3}-\mathrm{v}_{\mathrm{W}}^{3}\right], & 0 \leq \mathrm{v}_{\mathrm{W}} \leq \mathrm{v}_{\mathrm{O}}, \\
\overline{\mathrm{F}}_{\mathrm{W}}=-\frac{1}{2} \mathrm{C \rho A}\left(\frac{\mathrm{v}_{\mathrm{O}}^{2}}{3}-\mathrm{v}_{\mathrm{O}} \mathrm{v}_{\mathrm{W}}+\mathrm{v}_{\mathrm{W}}^{2}\right), & \mathrm{v}_{\mathrm{W}} \geq \mathrm{v}_{\mathrm{O}} \cdot
\end{array}
$$


Since the aerodynamic drag on the bicycle/rider system probably lies somewhere between the drag on a finite flat plate normal to the direction of air flow and that on a finite cylinder in this orientation, a value of unity for $C$ appears reasonable [26]. The mass density of air, $\rho$, under standard conditions is $1.23 \mathrm{~kg} / \mathrm{m}^{3}\left(0.0771 \mathrm{~b} / \mathrm{ft}^{3}\right)$ [26]. The projected area of the bicycle/rider system, $A$, may be taken as approximately $0.6 \mathrm{~m}^{2}\left(6 \mathrm{ft}^{2}\right)$.

With these data, Equations (29) and (30) show that for the typical bicycle with marginal braking capability $(\bar{a} / g=0.563)$ under zero wind conditions, the braking system furnishes only $0.558 \mathrm{~g}$ of deceleration, with the remaining $0.005 \mathrm{~g}$ provided by air resistance. This point is only academic however, since bicycles are not tested in a vacuum, and nothing is lost by attributing all of the braking action to the braking system.

Using Equations (28), (29) and (30), the effect of wind on the stopping distances attained by the typical bicycle with marginal braking capability may be calculated, with the following results:

\begin{tabular}{|c|c|c|c|c|c|}
\hline \multicolumn{2}{|c|}{ Wind speed, v } & \multicolumn{2}{|c|}{ Stopping distance, $\bar{s}$} & \multicolumn{2}{|c|}{ Error } \\
\hline$\overline{\mathrm{m} / \mathrm{s}}$ & $(\mathrm{mph})$ & $\mathrm{m}$ & $(f t)$ & $\mathrm{m}$ & ( ft \\
\hline 4.5 & $(10.0)$ & 4.63 & $(15.2)$ & 0.06 & $(0.2$ \\
\hline 3.0 & $(6.7)$ & 4.61 & $(15.1)$ & .04 & $(.1$ \\
\hline 2.2 & $(5.0)$ & 4.61 & $(15.1)$ & .04 & $(.1$ \\
\hline 0 & (0) & 4.57 & $(15.0)$ & 0 & $(c$ \\
\hline-2.2 & $(-5.0)$ & 4.51 & $(14.8)$ & -.06 & $(-.2$ \\
\hline-3.0 & $(-6.7)$ & 4.48 & $(14.7)$ & -.09 & $(-.3$ \\
\hline-4.5 & $(-10.0)$ & 4.42 & $(14.5)$ & -.15 & $(-.5)$ \\
\hline
\end{tabular}

It may be seen that if the maximum permissible wind speed is taken as $\pm 2.2 \mathrm{~m} / \mathrm{s}$ ( $\pm 5.0 \mathrm{mph}$ ) then the maximum error in stopping distance, due to the wind, is $+0.04,-0.06 \mathrm{~m}(+0.1,-0.2 \mathrm{ft})$. With this same wind speed a manufacturer calculated the error as $\pm 0.1 \mathrm{~m}$ ( $\pm 0.3 \mathrm{ft}$ ) [9]. While the rationale of the latter calculation is not obvious it is nonetheless clear that if the road tests were carried out alternately in opposite directions, and the results averaged, the net error would be very small. Using this approach, with permissible wind speeds up to $\$ 4.5 \mathrm{~m} / \mathrm{s}(10.0$ $\mathrm{mph})$, the error band would be only $+0,-0.05 \mathrm{~m}$ ( $+0,-0.2 \mathrm{ft}$ ) according to the above table, and zero according to the manufacturer's calculations. Since wind speed can be measured and suitably corrected for, the errors in stopping distance due to wind are systematic errors. However, recognizing that wind speed may change from one test to the next, it is probably more appropriate to consider these errors as though they were random. 


\section{ERROR ANALYSIS: INTERPRETATIONS AND IMPLICATIONS}

\subsection{Summary of Individual Error Analyses}

The preceding eight sections of this report have examined the errors that arise in the performance of the road test as a result of the variabilities of the several test parameters. The principal problem to be addressed in this section concerns the manner in which these errors accumulate. In order to facilitate discussion of this problem, some of the more pertinent results of the individual error analyses are summarized below. Since this summary cannot include all details and variations the reader is referred back to the appropriate sections of the report for further explanation and elaboration of the material presented here.

A11 of the errors cited here are given in units of meters (feet) and refer to deviations from the true stopping distance which properly characterizes the braking performance of the typical bicycle with marginal braking capability. Systematic errors are denoted by the symbol b and random errors by the symbol $r$. A positive error is one in which the measured (or measured and corrected) stopping distance exceeds the true stopping distance. A negative error is one in which the measured stopping distance is less than the true stopping distance.

(a) Error due to uncertainty in locating the starting point (Section $5.2):$

Using a starting line, $b \approx 0$ and $-0.6<\mathrm{r}<0.6 \mathrm{~m}(-2<\mathrm{r}<2 \mathrm{ft})$.

Using propelled markers, $-0.2<\mathrm{b}<0 \mathrm{~m}(-0.7<\mathrm{b}<0 \mathrm{ft})$ and $-0.02<$ $\mathrm{r}<0.02 \mathrm{~m}(-0.07<\mathrm{r}<0.07 \mathrm{ft})$.

(b) Error due to failure to track a straight path (Section 5.3):

Without guidance, $b \approx 0$ and $-0.37<\mathrm{r}<0 \mathrm{~m}(-1.2<\mathrm{r}<0 \mathrm{ft})$.

With guidance, $b \approx 0$ and $-0.04<\mathrm{r}<0 \mathrm{~m}(-0.1<\mathrm{r}<0 \mathrm{ft})$.

(c) Error due to rider's reaction time (Section 6):

$\mathrm{b} \approx 0$ and $-0.39<\mathrm{r}<0.89 \mathrm{~m}(-1.3<\mathrm{r}<2.9 \mathrm{ft})$.

(d) Error due to inaccuracy in measuring initial speed (Section 7.1):

With a speedometer, $\mathrm{b} \approx 0$ and $-0.27<\mathrm{r}<0.27 \mathrm{~m}(-0.9<\mathrm{r}<0.9$ $f t)$.

With a timing trap, $-0.12<\mathrm{b}<-0.10 \mathrm{~m}(-0.4<\mathrm{b}<-0.3 \mathrm{ft})$ and -0.09 $r<0.09 \mathrm{~m}(-0.3<\mathrm{r}<0.3 \mathrm{ft})$. 
(e) Error due to tire/pavement friction coefficient (Section 8):

With no limits on $\mu,-0.18<\mathrm{b}<1.39 \mathrm{~m}(-0.6<\mathrm{b}<4.6 \mathrm{ft})$ and $\mathrm{r}$ $=0$.

Without front wheel locking, $-0.18<b<0.12 \mathrm{~m}(-0.6<\mathrm{b}<0.4 \mathrm{ft})$ and $r=0$.

Without front wheel locking and with $\mu<1.0,-0.12<\mathrm{b}<0.12 \mathrm{~m}$ $(-0.4<b<0.4 \mathrm{ft})$ and $r=0$.

(f) Error due to inaccuracy in the applied lever force (Section 9.2):

$-0.03<b<0.11 \mathrm{~m}(-0.1<\mathrm{b}<0.4 \mathrm{ft})$ and $-0.11<\mathrm{r}<0.11 \mathrm{~m}$ $(-0.4<r<0.4 \mathrm{ft})$.

(g) Error due to the incorrect overweight-rider (and instrumentation) allowance (Sections 10.3 and 10.4):

With riders up to $120 \mathrm{~kg}(265 \mathrm{Ib}),-2.50<\mathrm{b}<0 \mathrm{~m}(-8.2<\mathrm{b}<0$ $f t$ ) and $r \approx 0$.

With riders up to $85 \mathrm{~kg}(187 \mathrm{lb}), 0.76<\mathrm{b}<0 \mathrm{~m}(-2.5<\mathrm{b}<0 \mathrm{ft})$ and $r * 0$.

With proposed new overweight allowance and riders up to $120 \mathrm{~kg}$ (265 1b), $-0.31<b<0 \mathrm{~m}(-1.0<\mathrm{b}<0 \mathrm{ft})$ and $\mathrm{r}<0$.

With fixed total payload, $b=0$ and $r \approx 0$.

(h) Error due to inclined roadway (Section 11):

With inclines up to +0.25 degrees, $-0.05<b<0.05 \mathrm{~m}(-0.2<b<$ $0.2 \mathrm{ft}$ ) and $r=0$.

With inclines up to 1 -percent grade, $-0.08<\mathrm{b}<0.08 \mathrm{~m}(-0.3<\mathrm{b}<$ $0.3 \mathrm{ft}$ ) and $\mathrm{r}=0$.

Averaging tests in both directions, $b=r=0$.

(i) Error due to wind (Section 12):

With winds up to $+4.5 \mathrm{~m} / \mathrm{s}(+10 \mathrm{mph}), \mathrm{b}=0$ and $-0.15<\mathrm{r}<0.06 \mathrm{~m}$ $(-0.5<: r<0.2 \mathrm{ft})$.

With winds up to $\pm 3.0 \mathrm{~m} / \mathrm{s}( \pm 6.7 \mathrm{mph}), \mathrm{b}=0$ and $-0.09<\mathrm{r}<0.04$ $\mathrm{m}\left(-0.3<\mathrm{r}<0 . \mathrm{f}_{\mathrm{ft}}\right)$. 
With winds up to $4.5 \mathrm{~m} / \mathrm{s}$ ( $10 \mathrm{mph}$ ), and averaging tests in both directions, $\mathrm{b}=0$ and $-0.05<\mathrm{I}<0 \mathrm{~m}(-0.2<\mathrm{I}<0 \mathrm{ft})$.

\subsection{The Measurement System: An Example}

In order to further facilitate discussion of the manner in which the individual errors accumulate, it is helpful to consider an example involving a specific, although hypothetical, measuring system. Let the following general characteristics define the measuring system:

(1) The typical bicycle with marginal braking capability.

(2) The starting point is located with propelled markers.

(3) The bicycle is steered along a relatively straight path into the stopping zone.

(4) Bicycle speed is measured with an electronic timing trap.

(5) The pavement of the test course is such that it offers a tire/pavement friction coefficient less than 1.0 and it does not induce front wheel locking.

(6) The combined mass of the rider and the instrumentation is limited to less than $120 \mathrm{~kg}(265 \mathrm{lb})$ and the instrumentation mass is distributed such that is does not significantly alter the cg location of the bicycle/rider system.

(7) The test course is level in the timing trap and the stopping zone.

(8) Wind speeds up to $\$ 4.5 \mathrm{~m} / \mathrm{s}( \pm 10.0 \mathrm{mph})$ are considered acceptable.

Within the current state of the art this measurement system could be considered both reasonably typical and reasonably good. With these characteristics and the error summary given above it is found that the applicable systematic error bands are

$$
\begin{array}{ll}
-0.2<b<0 \mathrm{~m} & (-0.7<b<0 \mathrm{ft}), \\
-0.12<b<-0.10 \mathrm{~m} & (-0.4<b<-0.3 \mathrm{ft}), \\
-0.12<b<0.12 \mathrm{~m} & (0.4<b<0.4 \mathrm{ft}), \\
-0.03<b<0.11 \mathrm{~m} & (-0.1<b<0.4 \mathrm{ft}), \\
-2.50<b<0 & (-8.2<b<0 \mathrm{ft}),
\end{array}
$$

and the random error bands are

$$
\begin{array}{ll}
-0.02<I<0.02 \mathrm{~m} & (-0.07<I<0.07 \mathrm{ft}), \\
-0.04<I<0 \mathrm{~m} & (-0.1<I<0 \mathrm{ft}),
\end{array}
$$




$$
\begin{array}{lll}
-0.39<r<0.89 \mathrm{~m} & (-1.3<\mathrm{r}<02.9 \mathrm{ft}), \\
-0.09<\mathrm{r}<0.09 \mathrm{~m} & (-0.3<\mathrm{r}<0.3 \mathrm{ft}), \\
-0.11<\mathrm{r}<0.11 \mathrm{~m} & (-0.4<\mathrm{r}<0.4 \mathrm{ft}), \\
-0.15<r<0.06 \mathrm{~m} & (-0.5<\mathrm{r}<0.2 \mathrm{ft}) .
\end{array}
$$

\subsection{Linear Accumulation of Errors}

If the various errors are simply added together algebraically, fol lowing one manufacturer's approach [27], then the overall error, e, is simply

$$
\bar{e}=\bar{b}+\bar{r}
$$

where

$$
\bar{b}=\Sigma b
$$

and

$$
\overline{\mathbf{r}}=\Sigma \mathrm{r} .
$$

This gives, for the example being considered,

and

$$
\begin{array}{ll}
-2.97<\overline{\mathrm{b}}<0.13 \mathrm{~m} & (-9.7<\overline{\mathrm{b}}<0.4 \mathrm{ft}), \\
-0.80<\overline{\mathrm{r}}<1.17 \mathrm{~m} & (-2.6<\overline{\mathrm{r}}<3.8 \mathrm{ft}), \\
-3.77<\overline{\mathrm{e}}<1.30 \mathrm{~m} & (-12.4<\overline{\mathrm{e}}<4.3 \mathrm{ft}) .
\end{array}
$$

These figures suggest that in any single test of this bicycle, which has braking capability just adequate to meet the 4.57-m (15.0-ft) stopping distance, the observed (i.e., the measured and corrected) stopping distance will deviate from $4.57 \mathrm{~m}(15.0 \mathrm{ft})$ by an amount between -3.77 and $+1.30 \mathrm{~m}(-12.4$ and $+4.3 \mathrm{ft})$. Stated differently, in any single test the observed stopping distance may fall anywhere between 0.80 and 5.87 m ( 2.6 and $19.3 \mathrm{ft}$ ). * This is a disturbingly broad range which, because the errors are predominantly negative, tends to favor bicycles with inadequate braking capabilities. If the overall error band is normalized, i.e., expressed as a band about its midpoint, a value of $\pm 2.535 \mathrm{~m}$ ( \pm 8.3 $\mathrm{ft}$ ) is obtained, which far exceeds even the $\pm 1.07-\mathrm{m}( \pm 3.5-\mathrm{ft})$ error band claimed by two manufacturers $[3,24]$.

*A measured stopping distance of only $0.80 \mathrm{~m}(2.6 \mathrm{ft})$ is, of course, unrealistic. However, a measured stopping distance of $4.26 \mathrm{~m}(14.0 \mathrm{ft})$ with a $120-\mathrm{kg}$ (265-1b) rider is quite conceivable and applying the overweight allowance brings the corrected stopping distance down to $0.80 \mathrm{~m}(2.6 \mathrm{ft})$. 
The significance of this result can be deceptive, however, because the systematic and random errors were simply added together in order to ascertain the overall error.

\subsection{Significance of Random and Systematic Errors}

For any given measuring system there is a single value of the overall systematic error -- rather than a range of values -- which is characteristic of the system. Although this value may be unknown, it does not change from test to test unless and until the measuring system is changed. The range of systematic errors therefore defines the variability between different laboratories, or between different measuring systems which might be employed in a single laboratory.

The random errors, on the other hand, do change from test to test even with an unchanging measuring system. The range of random errors therefore defines the test-to-test variability.

\subsection{Test-to-Test Variability}

The overall random error band calculated above indicates that, for the typical bicycle with marginally acceptable braking capability, the stopping distance observed in any single test with the sample measuring system will have a variability of $+1.17,-0.80 \mathrm{~m}(+3.8,-2.6 \mathrm{ft})$. While this error band is smaller, of course, than the overall error band, it is still very large. This result may also be deceptive, though, because it may suggest that it is equally likely for the observed stopping distance in any single test to fall anywhere within this band. However, this is not the case simply because it is not likely that the individual random errors $r$, due to the individual parameter variabilities, will all fall at their maximum or minimum values in any single test. Rather, it is highly unlikely that this will happen even once in any reasonable number of tests. Because of this, it is, perhaps, inappropriate to express the overall random error as the simple algebraic sum of the individual random errors. It is probably more realistic to estimate the overall random error as the square root of the sum of the squares of the individual random errors. This computation should utilize the form

$$
\bar{r}=\frac{S[r|r|]}{\sqrt{|\Sigma[r|r|]|}}
$$

rather than, simply, $\bar{r}=\sqrt{\Sigma r^{2}}$ in order to retain the algebraic signs of the individual errors. For the example being considered, this computation shows that the probable overall random error band is

$$
-0.44<\overline{\mathrm{r}}<0.91 \mathrm{~m} \quad(-1.4<\mathrm{r}<3.0 \mathrm{ft}) .
$$

(When the overall random error is computed in this way it becomes immediately obvious that it is dominated by only one of the individual 
random errors, namely, that due to the variability in the rider's reaction time.)

The magnitude of this test-to-test variability raises a serious question about the capability of a single test result to serve as the basis for judging the adequacy of a bicycle's braking system. For example, suppose that the overall systematic error of the system being considered is $-0.50 \mathrm{~m}(-1.6 \mathrm{ft})$. Then, because of the test-to-test variability, the observed stopping distance in any single test could range from 3.63 to $4.98 \mathrm{~m}$ ( 11.9 to $16.3 \mathrm{ft}$ ) for the bicycle with marginal braking capability.

Means for reducing the effects of this test-to-test variability will be presented later.

As pointed out above, the overall random error band depends primarily upon the error band attributable to variations in the rider's reaction time. Therefore, in any given laboratory, the test-to-test variability in observed stopping distance will reflect the ability of the rider to maintain consistent reaction times. In this connection it may be noted that it is clearly in a manufacturer's interest to strive for short reaction times in his tests, while the motivation to achieve this may not be so great in an independent laboratory. Thus, it is conceivable that the average reaction time of a rider employed by a manufacturer may be less than the average reaction time of a rider in another laboratory. The difference between a rider's average reaction time and the "standard" value of 0.15 seconds actually represents a systematic error, rather than a random error. This systematic error has not been treated explicitly in this analysis but it should be kept in mind that it could contribute to the lab-to-lab variability in observed stopping distance which is examined below.

\subsection{Lab-to-Lab Variability}

For laboratories which employ measurement systems that conform to the general specifications set forth in Section 13.2, the lab-to-lab variability is defined by the overall systematic error band calculated above, namely,

$$
-2.97<\overline{\mathrm{b}}<0.13 \mathrm{~m} \quad(-9.7<\overline{\mathrm{b}}<0.4 \mathrm{ft}) .
$$

However, while this represents the maximum possible range of systematic errors it does not represent the probable range. In other words, it is highly unlikely that all of the individual systematic errors will fall at their respective minima or maxima in any single laboratory. Recognizing this, and following the procedure used above for random errors, it is 
estimated that the probable range of the overall systematic error is given by

$$
\bar{b}=\frac{\sum[b|b|]}{\sqrt{|\Sigma[b|b|]|}}
$$

which yields, for the measuring systems under consideration,

$$
-2.51<\bar{b}<0.13 \mathrm{~m} \quad(-8.2<\overline{\mathrm{b}}<0.4 \mathrm{ft}) .
$$

The lab-to-lab variability, which this overall systematic error band defines, is so huge that it tends to render meaningless any comparisons of results between different laboratories. Fortunately, however, this overall systematic error is thoroughly dominated by only one of the individual systematic errors, namely, that due to the incorrect overweight rider allowance, and this source of error is amenable to rectification.

Three ways to reduce the systematic error due to the incorrect overweight rider allowance were discussed in Sections 10.3 and 10.4 . If the ISO approach [6] were adopted, the combined mass of the rider and the instrumentation would be limited to a maximum of $85 \mathrm{~kg}$ (187 lb). In this circumstance it can be shown that the probable overall systematic error band would be reduced to

$$
-0.80<\bar{b}<0.13 \mathrm{~m} \quad(-2.6<\overline{\mathrm{b}}<0.4 \mathrm{ft})
$$

a tremendous improvement.

If the overweight rider allowance were changed from $0.30 \mathrm{~m}$ per 4.5 $\mathrm{kg}(1.0 \mathrm{ft}$ per $10 \mathrm{lb})$ to $0.11 \mathrm{~m}$ per $4.5 \mathrm{~kg}(0.35 \mathrm{ft}$ per $10 \mathrm{lb})$ then, even with riders plus instrumentation up to $120 \mathrm{~kg}$ ( $265 \mathrm{lb}$ ), the probable overall systematic error band would be further reduced to

$$
-0.41<\bar{b}<0.13 m \quad(-1.3<\bar{b}<0.4 \mathrm{ft}) .
$$

Finally, if it were required that all tests be carried out with the same total payload (rider + instrumentation + added mass) then the systematic error due to the overweight allowance would disappear entirely, and the probable overall systematic error would be only

$$
-0.26<\bar{b}<0.13 \mathrm{~m} \quad(-0.9<\bar{b}<0.4 \mathrm{ft}) .
$$

The lab-to-lab variability implied by this systematic error band is quite acceptable in comparison with the larger test-to-test variabilities of the measuring systems. 


\subsection{Reducing the Effects of Test-to-Test Variability}

As shown earlier, the probable overall random error band of the systems under consideration, which defines the test-to-test variability, is

$$
-0.44<\overline{\mathrm{r}}<0.91 \mathrm{~m} \quad(-1.4<\overline{\mathrm{r}}<3.0 \mathrm{ft}) .
$$

With this variability, the question was raised as to whether the result of a single test is adequate to determine whether a bicycle's braking capability is or is not acceptable. Actually, the Bicycle Safety Regulation does not specify that this determination should, in fact, be based on a single test. With the option of using the results of several test runs, rather than one, several methods have been proposed for reducing the uncertainty that stems from the test-to-test variability.

One method is based on using the average results of several test runs. The random error band for the average of a number of test runs is smaller than the random error band for a single test run. In principle, the more tests the better, since the random error band for the average of a large number of test runs would be quite small. Following this approach, an independent laboratory conducted a test program in which, whenever tests of a particular bicycle exhibited an especially large disparity in observed stopping distances, the tests were continued until a reasonable consistency was developed and the five shortest distances were averaged [10].

However, multiple testing of this kind is both difficult and expensive and, perhaps with this in mind, a manufacturer suggested, simply, that each bicycle be subjected to five test runs with the average stopping distance reported as the final result $[3,24]$.

A variation of the averaging method is used in motorcycle brake testing [7]. In this approach, four test runs are performed and only one of the observed stopping distances is required to be within the specified criterion in order for the braking system to be considered acceptable. This approach makes use of the "randomness" of random errors, so to speak, contending that in at least one out of four runs the overall random error will not fall on the positive side of its band.

In an entirely different method an allowance is incorporated into the stopping distance criterion to compensate for the random errors. Thus, one nation's delegation to the ISO proposed that the stopping distance criterion be raised from $4.57 \mathrm{~m}$ ( $15.0 \mathrm{ft})$ to $5.5 \mathrm{~m}$ (18 ft) and that none of the stopping distances observed in five test runs exceed this criterion [18]. This method also has merit, since in five test runs it may be expected that the overall random error will approach its probable maximum positive value at least once. 
The U.S. delegation to the ISO proposed a combination of the two general methods, requiring that the average stopping distance recorded in five test runs not exceed a value of $5.5 \mathrm{~m}$ (18 ft) [18], and the ISO adopted this proposal [28]. However, the rationale behind this approach is not immediately evident.

In summary, therefore, either of the two general methods discussed above could be used to counteract the effects of the test-to-test variability. If the first method is used, whereby the average stopping distance recorded in a number of test runs is used, it remains only to suitably select the required number of runs using statistical techniques. If the second method is used, in which an allowance is added to the stopping distance criterion and it is required that none of the observed stopping distances in a series of test runs exceed this value, then the number of test runs used is not as critical. A suitable value for the allowance should be based upon the maximum probable positive random and systematic errors. For the systems under consideration,

$$
\overrightarrow{\mathrm{e}}_{\max }=\overline{\mathrm{b}}_{\max }+\overline{\mathrm{r}}_{\max }=0.13+0.91=1.04 \mathrm{~m}(3.4 \mathrm{ft}) \text {. }
$$

It appears, from this calculation, that an allowable stopping distance of $5.5 \mathrm{~m}$ ( $18 \mathrm{ft}$ ) is, in fact, a reasonably suitable value for use with this method, which requires that none of the stopping distances exceed the allowable value.

The simplest approach would follow the practice used with motocycles. In this approach the 4.57-m (15.0-ft) criterion would be retained but, recognizing the test-to-test variability, it would only be required that one out of several test runs satisfy the criterion in order for the braking system to be judged adequate.

\section{DISCUSSION}

This section of the report is not a discussion of the results which were obtained. Rather, it presents a few discrete observations which are relevant to the subject matter at hand but only peripheral to the main thrust of the report.

\subsection{Brake Sensitivities}

In Section 2.3 the observation was made that a given brake system which may be adequate for one bicycle may be entirely inadequate for another. To illustrate this point, the following tabulation shows the 
brake sensitivity $Z$ on each of the three which is required to provide marginal braking capability kinds of bicycles examined in this report:

\begin{tabular}{lc}
\multicolumn{1}{c}{ Bicycle } & $\underline{Z_{0}}$ \\
Typical & 2.32 \\
Conventional & 1.99 \\
High rise & 1.89
\end{tabular}

This calculation was based on Equation (1) and Equation (20), which assumes that the front wheel rolls and the rear wheel skids during the stopping process. This, of course, is the usual situation with most bicycles, which are designed to have equal brake sensitivities on the front and rear wheels.

One manufacturer, however, has pointed out -- and rightly so -that there are advantages to using unequal brake sensitivities on the front and rear wheels. By using a higher brake sensitivity on the front wheel, and a correspondingly lower value on the rear wheel, enhanced braking capability is achieved with the same combined brake sensitivity, particularly under hard braking conditions [27]. Bicycles equipped in this way may be expected to attain higher deceleration rates, with both wheels rolling, than bicycles with conventional braking systems.

The distribution of total brake sensitivity between the front and rear wheels is a variable which was not explicitly treated in this report. All calculations of braking performance with both wheels rolling were based on the assumption of equal brake sensitivities, front and rear.

\subsection{Optimum Tire/Pavement Friction Coefficients}

Although a tire/pavement friction coefficient of 0.75 was adopted in this report for the purpose of defining marginal braking capability, it should not be inferred that this is, in fact, the best value to use for road testing. Rather, it was shown that the error due to $\mu$ is quite small so long as it is less than 1.0 yet high enough to avoid front wheel locking. The following tabulation shows the minimum value of $\mu$ which can be used for the road test without front wheel locking:

$$
\text { Bicycle } \quad \underline{\mu_{\text {min }}}
$$

$\begin{array}{lr}\text { Typical } & 0.547 \\ \text { Conventional } & .531 \\ \text { High rise } & .528\end{array}$

It is thus evident that there is a wide range of acceptable $\mu$ values

to choose from. Therefore, it is prudent to select a value on the basis of other advantages. In order to satisfy the specified stopping distance 
criterion $\mu$ must be not less than 0.563. In order to avoid pitchover except, perhaps, with very unusual bicycles, the data in Section 10.5 suggest that $\mu$ should be less than 0.7 . It thus appears that a value in the range 0.60 to 0.65 would be optimum for the road test in that it would enable the stopping distance criterion to be satisfied without an ever-present danger of pitchover while, at the same time, contributing to good measurement accuracy. The use of higher values of $\mu$ would increase the pitchover hazard but would not reduce the stopping distance significantly.

\subsection{Other Kinds of Bicycles}

The error analysis described in this report was concerned only with bicycles equipped with hand-lever operated brakes, front and rear, which can attain an initial speed of $24 \mathrm{~km} / \mathrm{h}$ ( $15 \mathrm{mph}$ ) on a level test course. The Bicycle Safety Regulation, however, does not restrict itself to such bicycles. Rather, it provides for road tests on bicycles equipped with a variety of brake options and for low-speed bicycles as well. While the braking performances of these other kinds of bicycles were not addressed directly in the analyses, it is believed that the analytical procedures which were used provide ample guidance for the preparation of applicable error analyses for virtually all kinds of commercially available bicycles.

\subsection{Other Test Parameters}

The multitude of test parameters which influence the results of the road test were not all included in the error analyses, although it is felt that all of the important ones were given reasonably thorough consideration. Some parameters, such as rolling friction in the bicycle wheel bearings, were not treated thoroughly because their effects on stopping distance are believed to be only minor in comparison with the effects of the important parameters. Other parameters, such as the condition of the wheel rims where the brake pads make contact, were ignored because of insufficient data upon which to base an analysis. The effects of such parameters, however, can generally be rendered negligible through good testing technique; in the case of the wheel rims, for example, by cleaning the rims with a quick-drying solvent prior to each test run.

\subsection{Improved Testing Techniques}

While the error analyses were primarily concerned with establishing the 1 imits, or bounds, of each source of error, it should not be inferred that these limits are either rigid or necessarily applicable in all cases. Certainly, the error bands which apply to any given laboratory can be reduced by careful attention to detail and good testing technique. A few suggestions have been made in this regard. For example, if alternate test runs on a bicycle are made in opposite directions then the errors due to an inclined roadway and wind are significantly reduced in the average test result. 
It has also been demonstrated that automatic systems for applying the required forces to the handbrake levers are feasible, and that they effectively eliminate variability in rider reaction times and the errors which result therefrom [9]. Still another technique which merits consideration involves the use of a decelerometer to measure peak performance during the road test. One such device, reportedly, has an accuracy within \pm 1 percent and, if used properly, eliminates the errors due to rider reaction time while, at the same time, obviating the need for accurate measurement of initial speed [5].

In this connection it may be noted that a ruad test may not, in fact, be the best way to evaluate a bicycle's braking capability. It has been suggested [13], for example, that a dynamometer-type laboratory test of one kind or another, such as is used to measure braking performance on some motorized vehicles (cf [29]), may be preferable. While it is outside the scope of this report to evaluate different test methods, one aspect of such an evaluation is relevant to the present discussion. The major sources of error in the road test (overweight riders and rider reaction times), as well as its principal operational difficulty (avoiding pitchover), are all absent in a properly conceived laboratory test.

\section{CONCLUSIONS}

1. Concepts of brake sensitivity and braking capability were defined, which enable a bicycle's braking performance to be quantified and discussed in tangible, rational terms. Other concepts, such as typical bicycle characteristics and marginal braking capability, were developed to establish a framework against which various braking performances could be evaluated.

2. The test parameters which influence the results of the CPSC road test for braking performance were identified and the errors (or variabilities) in observed stopping distance, which result from variations in these parameters, were examined. Insofar as possible, these error analyses were based upon critical evaluations of available test data. However, in some cases the available data are inadequate and the error analyses had to be based upon theoretical considerations.

3. A two-dimensional analysis of the kinetics of bicycle braking was developed. This yielded equations of motion for the various combinations of skidding and rolling wheels and provided the basis for estimating the errors attributable to variations in several of the test parameters. In addition, it enabled formulation of the threshold conditions for pitchover-type instabilities.

4. The various errors encountered in the performance of the road test were combined, according to whether they are random or systematic in nature, to arrive at quantitative estimates of the test-to-test 
variability and the $1 \mathrm{ab}-\mathrm{to}-1 \mathrm{ab}$ variability of observed stopping distance. These variabilities were found to be excessively large, casting doubt on the validity of the test method as presently promulgated.

5. With reasonably good testing technique -- including only mild restrictions on the types of pavements which might be used -- it was found that the $1 \mathrm{ab}-\mathrm{to}-\mathrm{ab}$ variability is dominated by errors which result from the incorrect overweight-rider allowance specified in the Bicycle Safety Regulation. Three alternative proposals were introduced, for changes in the specified method of accommodating different rider masses, any of which would reduce the lab-to-lab variability to more acceptable levels.

6. The test-to-test variability, with reasonably good testing technique, was shown to depend primarily on the variability of the test rider's reaction times. Methods for reducing the effects of this variability on the validity of the test results are proposed, based primarily on the use of a multiple-testing approach. 


\section{REFERENCES}

1. Dunn, S. E., Banning of Hazardous Bicycles; Establishment of Safety Requirements, Federal Register 39, No. 137, pp 26100 - 26112 (National Archives of U.S., Washington, July 16, 1974).

2. Dunn, S. E., Bicycle Banning and Safety Regulations, Federal Register 40, No. 116, pp 25480 - 25494 (National Archives of U.S., Washington, June 16, 1975).

3. Anon., Proceedings of the February 3, 1975, public meeting of CPSC staff, bicycle manufacturers and others, official transcript (undated).

4. Anon., Proceedings of the May 8, 1975, public meeting of CPSC staff, bicycle manufacturers and others, official transcript (undated).

5. Anon., Braking Performance, Report of meeting of WG1-Paris, Feb. 28, 1975.

6. International Organization for Standardization, Braking Performance, Document No. ISO/TC149/SC1(WG1-2) 41E (revised) (British Standards Institution, London, undated).

7. U.S. Department of Transportation, Motorcycle Brake System, Federal Motor Vehicle Safety Standard No. 122 (Washington, April 1972).

8. Anon., Test Methods for Measuring the Braking Performance of Bicycles, Fichtel \& Sachs AG (Oct. 10, 1975 [sic]).

9. Hesketh, G. P., An Investigation into Performance Testing of Bicycle Brakes, Raleigh Industries Ltd, Report int. 90 (Jan. 22, 1975).

10. McConne11, W. H., and Parks, J. T., Capability Criteria of Bicycle Braking Systems, U. of Iowa, Engineering Report on Contract FDA 73-6 (Dec. 7, 1972).

11. Lewis, G. D., The Manoeuvrability and Braking Performance of Sma11Wheeled Bicycles when Ridden by Children, Transportation and Road Research Laboratory, Report LR 500 (Crowthorne, Berkshire, U.K., 1973). 
12. Palsedge, J. and Szymski, E., Test Report No. 497, Schwinn Bicycle Co. (Feb. 14, 1975).

13. Marlowe, D. E., The CPSC Road Test of Bicycle Braking Performance Experimental Evaluation, NBSIR 75-755 (Aug. 1975).

14. Palsedge, J., Test Report No. 507, Schwinn Bicycle Co. (Feb. 25, 1975).

15. Rice, R. S. and Roland, R. D., Jr., An Evaluation of the Performance and Handling Qualities of Bicycles, Cornell Aeronautical Laboratory, Technical Report No. VJ-2888-K (April 1970).

16. Anon., Speed Measuring Instruments, James G. Biddle Co., Bulletin 35b (Plymouth Meeting, Pa., April 1975).

17. Palsedge, J., Test Report No. 332, Schwinn Bicycle Co. (Aug. 30, 1974).

18. International Organization for Standardization, Report of the Meeting of Working Group 1 - Braking Performance, Held in London, Thursday 24 October 1974, Document No. ISO/TC149/SC1 (London 1974 - 3) 33, Exhibit 3 (British Standards Institution, London, Nov. 1974).

19. Ibayashi, H., Opinion from Our Association on the Task of ISO/TC149/SC1, Japan Bicycle Industry Association (undated).

20. Doughtie, V. L., Mechanisms and Machine Elements, Section 7 of Kent's Mechanical Engineers' Handbook, Design and Production Volume, C. Carmichael (ed), 12th edition, p 7-30 (John Wiley \& Sons, N.Y., 1961).

21. Fuller, D. D., Friction, Chapter 3 in Marks' Standard Handbook for Mechanical Engineers, T. Baumeister (ed), 7th edition, p 3-39 (McGrawHill Book Co., N.Y., 1967).

22. Pettersson, R., Halkfri Faerg till Betong-och Asfaltunderlag (Skidproof Dyes for Concrete and Asphalt), Research Institute of National Defence (Stockholm, Feb. 1973). 
23. American Society for Testing and Materials, Standard Method of Test for Skid Resistance of Paved Surfaces Using a Ful1-Scale Tire, 1973 Annual Book of ASTM Standards, Part 11 (1973).

24. McWhirter, B. J. and Luking, W. H., Comments on Proposed Amendments to the Bicycle Banning and Safety Regulations, submitted to the Consumer Products Safety Commission on behalf of Raleigh Industries Ltd and Raleigh Industries of America, Inc., July 14, 1975.

25. Szymski, E. J., Letter to K. Edinger, Feb. 18, 1975.

26. Dwinnel1, J. H., Principles of Aerodynamics, first edition (McGrawHill Book Co., N.Y., 1949).

27. Raleigh Industries Ltd, Supplementary Information to That Put Forward by J. F. Harriman to the CPSC [at the public meeting] on 10th September 1974, Exhibit A of Reference 24.

28. International Organization for Standardization, Document No. ISO/TC149/SC1 (London - 1974) 33, 1oc. cit. [18], Exhibit 2.

29. Lavrentev, N., Method of Checking and Adjusting Brakes of the GAZ-21 on the Basis of Braking Time, Army Foreign Science and Technology Center, FSTC-HT-23-1743-73 (Charlottesville, Va., March 5, 1974). Translated from Avtomobilnyy Transport, No. 1, pp 25-26 (1972) by Leo Kanner Associates (Redwood City, Calif.).

30. Dunn, S. E., Bicycle Safety Regulations, Federal Register 40, No. 220, pp 52815-52825 (National Archives of U.S., Washington, Nov. 13, 1975). 
APPENDIX

\section{List of Symbols}

A projected area of bicycle/rider system normal to the direction of motion

a linear deceleration of bicycle

$\bar{a} \quad$ maximum deceleration in the road test

B braking capability, Equation (2)

b systematic error

$\overline{\mathrm{b}} \quad$ overall systematic error

$\bar{b}_{\max }$ maximum positive overall systematic error

C aerodynamic drag coefficient

D wheel diameter

$\overline{\mathrm{e}}$ overall error

$\overline{\mathrm{e}}_{\max }$ maximum positive overall error

$\mathrm{F}_{\mathrm{b}}$ tangential retarding force applied to wheel by brake pads

$F_{b f}$ tangential retarding force applied to front wheel by brake pads

$F_{b r}$ tangential retarding force applied to rear wheel by brake pads

$\mathrm{F}_{\mathrm{W}}$ aerodynamic drag force on bicycle/rider system

$\overline{\mathrm{F}}_{\mathrm{W}}$ approximate aerodynamic drag force on bicycle/rider system

$F_{x f}$ horizontal component of resultant force at front wheel axis

$F_{x r}$ horizontal component of resultant force at rear wheel axis

$F_{y f}$ vertical component of resultant force at front wheel axis

$F_{y r}$ vertical component of resultant force at rear wheel axis 
$f_{f}$ horizontal component of resultant force at front wheel/pavement interface

$\mathrm{f}_{\mathrm{r}}$ horizontal component of resultant force at rear wheel/pavement interface

g acceleration of gravity, $9.80665 \mathrm{~m} / \mathrm{s}^{2}\left(32.1740 \mathrm{ft} / \mathrm{s}^{2}\right)$

$\mathrm{H}$ height of $\mathrm{cg}$ of bicycle/rider system above the pavement

h height of $\mathrm{cg}$ of bicycle frame/rider combination above the wheel axes

I mass moment of inertia of bicycle wheel

$k=\left\{\begin{array}{l}+1 \text { if } v-v_{w}>0 \\ -1 \text { if } v-v_{w}<0\end{array}\right.$

L whee1 base

\& distance of $\mathrm{cg}$ of bicycle/rider system aft of the front wheel axis

$\mathrm{M}_{\mathrm{b}}$ mass of bicycle

$M_{f}=M_{b}-2 M_{w}$, mass of bicycle frame

$M_{r}$ mass of rider

$M_{W}$ mass of wheel

m mechanical advantage of caliper handbrake assembly

P force applied to handbrake lever by rider

Q squeezing force applied to wheel rim by brake pads

q distance of $\mathrm{cg}$ of bicycle frame/rider combination aft of the front wheel axis

$R_{f}$ vertical component of resultant force at front wheel/pavement interface

$R_{r}$ vertical component of resultant force at rear wheel/pavement interface

r random error

$\bar{r} \quad$ overall random error

$\bar{r}_{\max }$ maximum positive overal1 random error 
$\bar{s} \quad$ stopping distance in road test

$\bar{s}_{c} \quad$ stopping distance in road test, corrected for infial speed

$\bar{s}_{\mathrm{m}}$ measured stopping distance in road test

$t_{1}$ rider reaction time

v bicycle speed

$v_{0} \quad$ initial bicycle speed

$v_{\text {om }}$ measured initial bicycle speed

$\mathrm{v}_{\text {os }}$ specified initial bicycle speed

$v_{w}$ component of wind speed in direction of bicycle motion

$\mathrm{W}_{\mathrm{b}} \quad=\mathrm{M}_{\mathrm{b}} \mathrm{g}$

$\mathrm{W}_{\mathrm{f}} \quad=\mathrm{M}_{\mathrm{f}} \mathrm{g}$

$\mathrm{W}_{\mathrm{r}}=\mathrm{M}_{\mathrm{r}} \mathrm{g}$

$\mathrm{W}_{\mathrm{w}} \quad=\mathrm{M}_{\mathrm{w}} \mathrm{g}$

Z brake sensitivity, Equation (1)

$Z_{0} \quad$ brake sensitivity for marginal braking capability $(B=1)$

$\alpha \quad$ angular deceleration of bicycle wheel

$B \quad$ angle of incline of test course

$\theta_{f}$ included angle, at the front wheel axis, of the brake pads from the vertical, Figure 2

$\theta_{r}$ included angle, at the rear wheel axis, of the brake pads from the vertical, Figure 1

$\mu \quad$ coefficient of friction at the tire/pavement interface 
$\mu_{\text {min }}$ minimum coefficient of friction at the tire/pavement interface for avoiding front wheel locking in the road test

$\checkmark \quad$ coefficient of friction between brake pads and wheel rim

$\rho \quad$ mass density of air 
Table 1 - Characteristics of the Typical Bicycle

Mass of bicycle, M Mass of bicycle frame, $M$ Mass of bicycle wheel, $\mathrm{M}_{\mathrm{W}}^{\mathrm{f}}$ Whee1 diameter, $D$ Wheel base, I
$18 \mathrm{~kg}$

$14 \mathrm{~kg}$

$2 \mathrm{~kg}$

$660 \mathrm{~mm}$

$1000 \mathrm{~mm}$
(39.7 1b)

$(30.9 \mathrm{lb})$

$(4.4$ 1b)

(26.0 in)

$(39.4 \mathrm{in})$

Nondimensional coordinates of the center of gravity of the bicycle with a $68.1-\mathrm{kg}(150$ 1b) rider:

Distance aft of the front wheel axis, $\ell / L \quad 0.60$

Distance above the pavement, H/L

0.85 
Table 2 - High Rise Bicycle [15]

\section{Characteristics}

Mass of bicycle, $\mathrm{M}_{\mathrm{b}}$ Mass of bicycle frame, M Mass of bicycle wheel, $\mathrm{M}_{W}^{\mathrm{I}}$ Wheel diameter, D Wheel base, L
$17.7 \mathrm{~kg}$

$14.1 \mathrm{~kg}$

$1.8 \mathrm{~kg}$

$533 \mathrm{~mm}$

$889 \mathrm{~mm}$
(39 1b)

(31 1b)

(4 1b)

(21 in)

(35 in)

Effect of Rider Mass on CG Location

\begin{tabular}{|c|c|c|c|}
\hline \multicolumn{2}{|c|}{$\mathrm{M}_{r}$} & $\ell / L$ & $\mathrm{H} / \mathrm{L}$ \\
\hline $\mathrm{kg}$ & (1b) & & \\
\hline 0 & (0) & 0.528 & 0.528 \\
\hline 45.4 & $(100)$ & 0.700 & 0.800 \\
\hline 68.1 & (150) & 0.732 (a) & 0.879 (a) \\
\hline 86.2 & (190) & 0.757 & 0.943 \\
\hline
\end{tabular}

(a) Interpolated. 


\section{Characteristics}

$\begin{array}{lrr}\text { Mass of bicycle, M } & 17.7 \mathrm{~kg} & \text { (39 1b) } \\ \text { Mass of bicycle frame, Mf } & 13.1 \mathrm{~kg} & \text { (29 1b) } \\ \text { Mass of bicycle wheel, } \mathrm{M}_{\mathrm{w}} & 2.3 \mathrm{~kg} & \text { (5 1b) } \\ \text { Wheel diameter, D } & 673 \mathrm{~mm} & (26.5 \mathrm{ln}) \\ \text { Wheel base, L } & 1092 \mathrm{~mm} & (431 \mathrm{n})\end{array}$

Effect of Rider Mass on CG Location

\begin{tabular}{|c|c|c|c|}
\hline \multicolumn{2}{|c|}{$\mathrm{M}_{r}$} & \multirow[t]{2}{*}{$2 / L$} & \multirow[t]{2}{*}{$\mathrm{H} / \mathrm{L}$} \\
\hline $\mathrm{kg}$ & (1b) & & \\
\hline 0 & (0) & 0.512 & 0.459 \\
\hline 45.4 & $(100)$ & 0.593 & 0.698 \\
\hline 68.1 & $(150)$ & 0.635 (a) & $0.750(a)$ \\
\hline 86.2 & (190) & 0.669 & 0.791 \\
\hline
\end{tabular}

(a) Interpolated. 


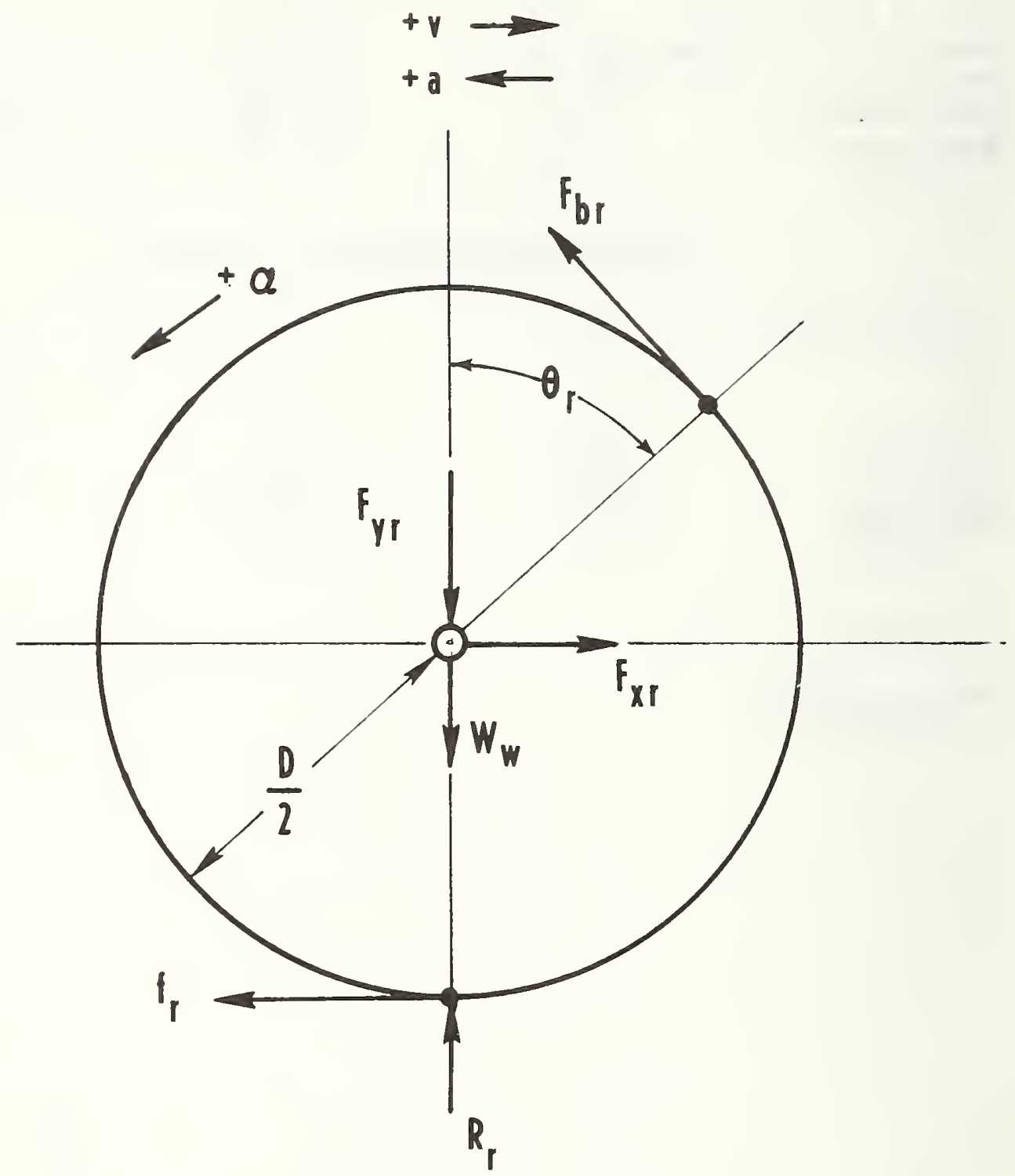

Figure 1. Free-body diagram of bicycle rear wheel. 


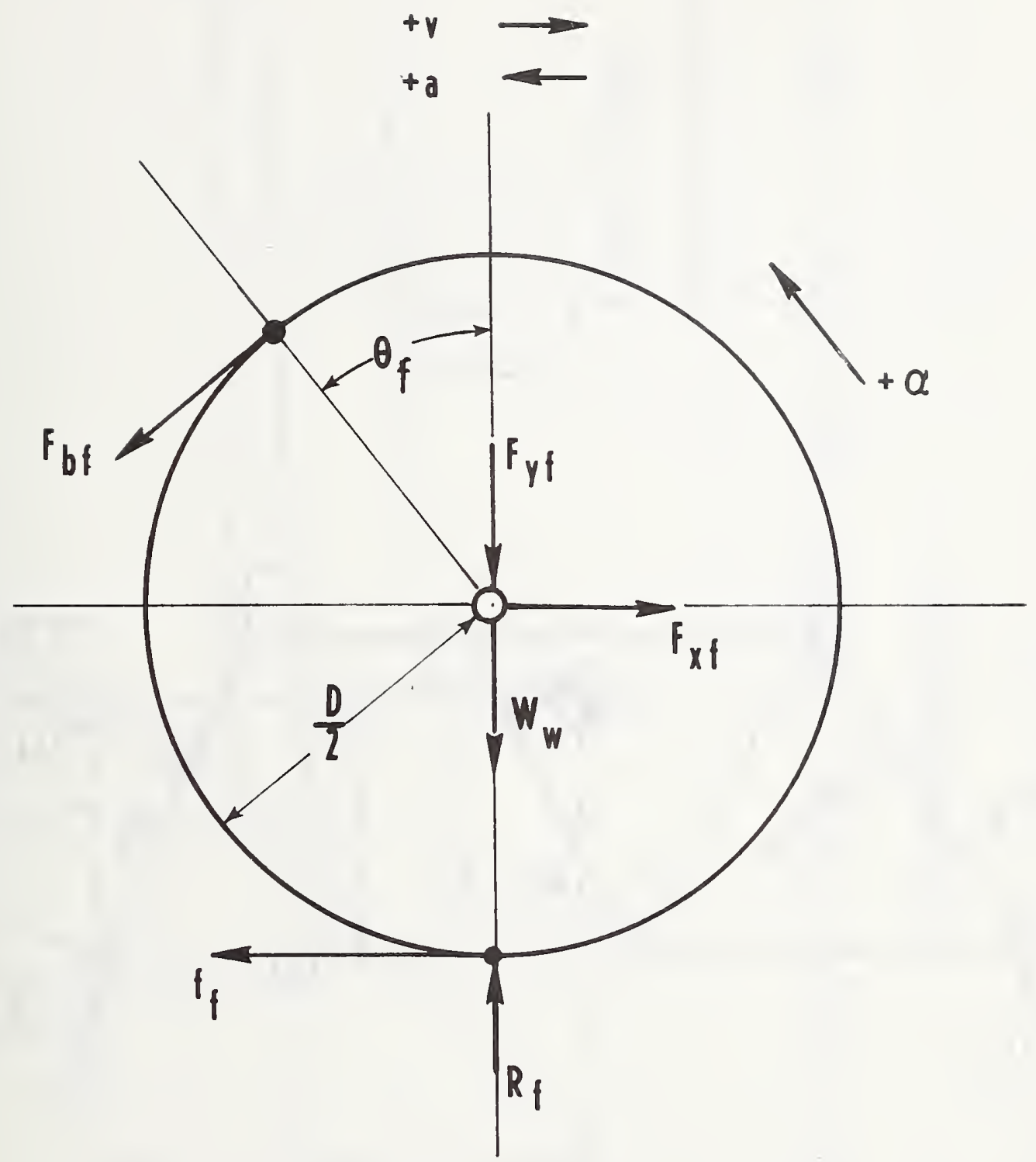

Figure 2. Free-body diagram of bicycle front whee1. 

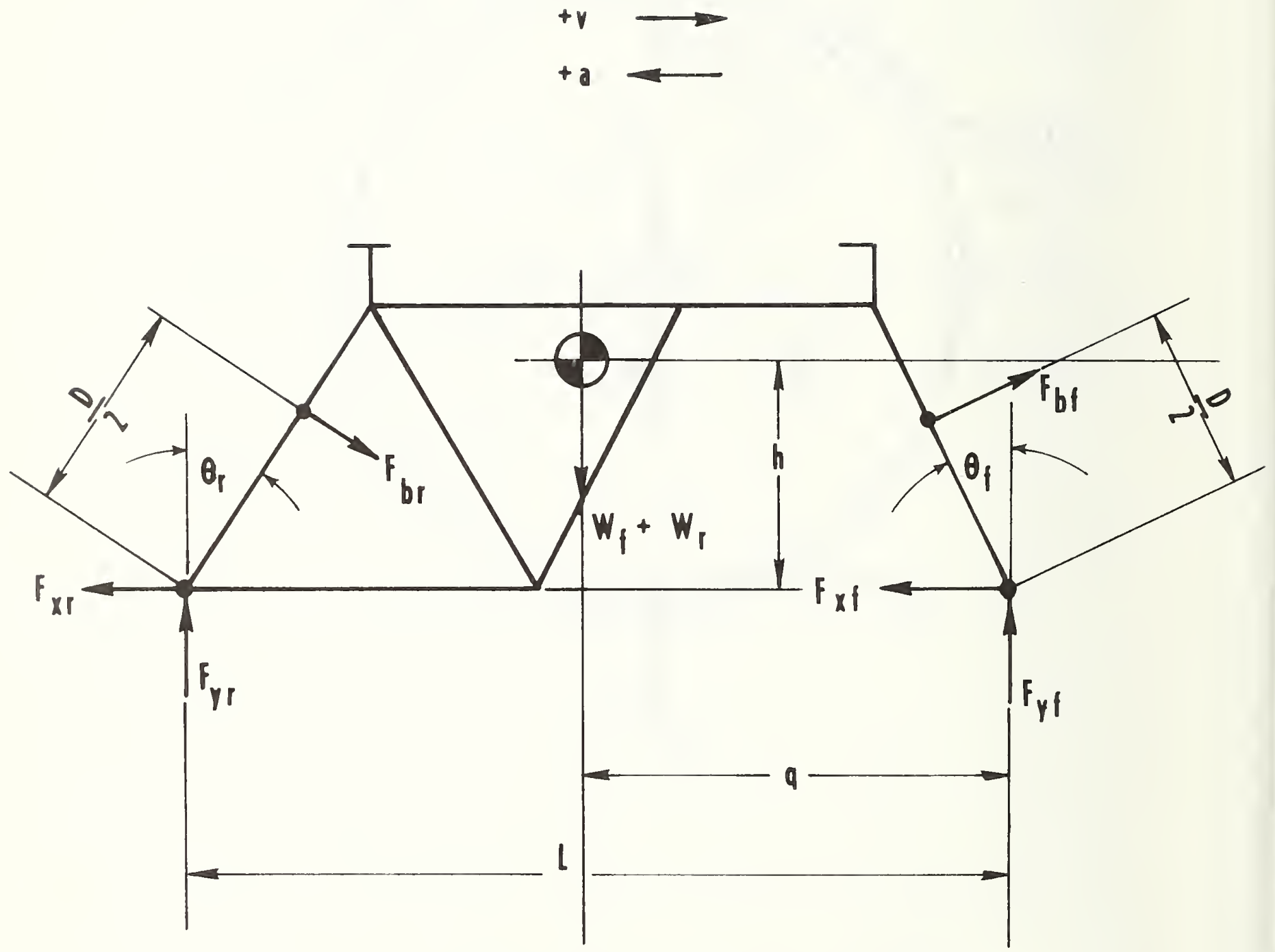

Figure 3. Free-body diagram of bicycle frame-rider combination (rider not shown). 


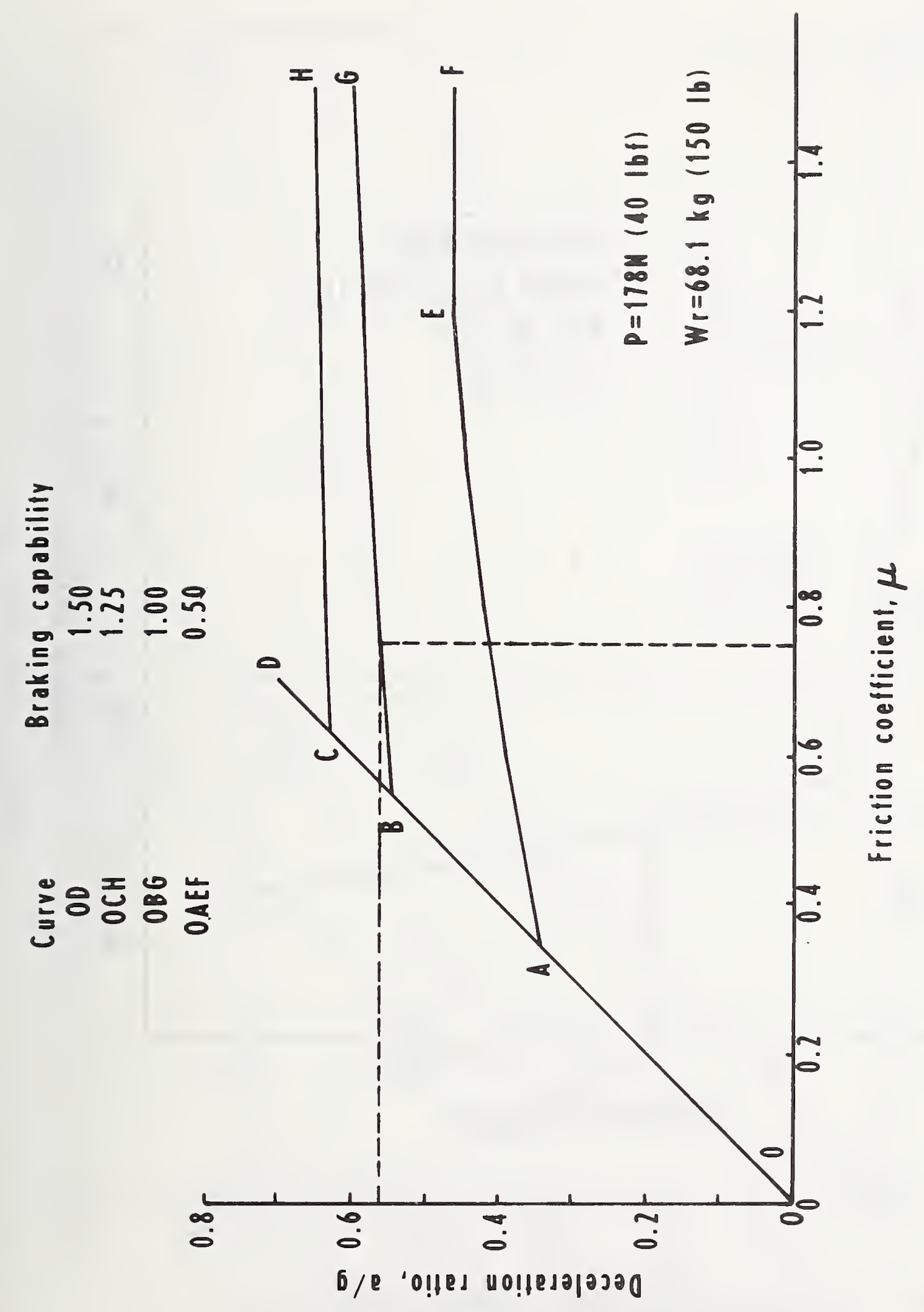




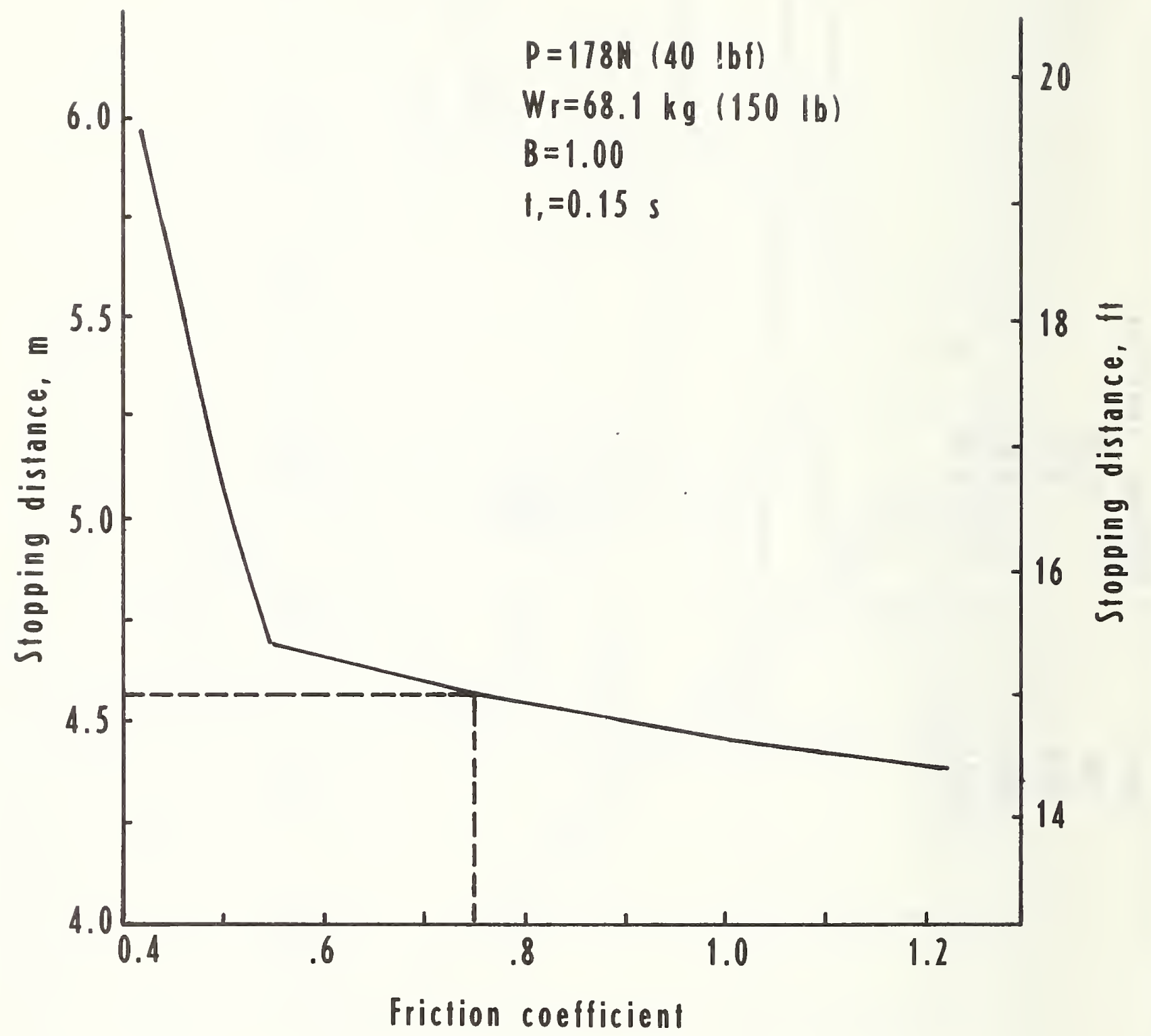

Figure 5. Effect of tire/pavement friction coefficient on the stopping distance of the typical bicycle with marginal braking capability under the specified test conditions. 


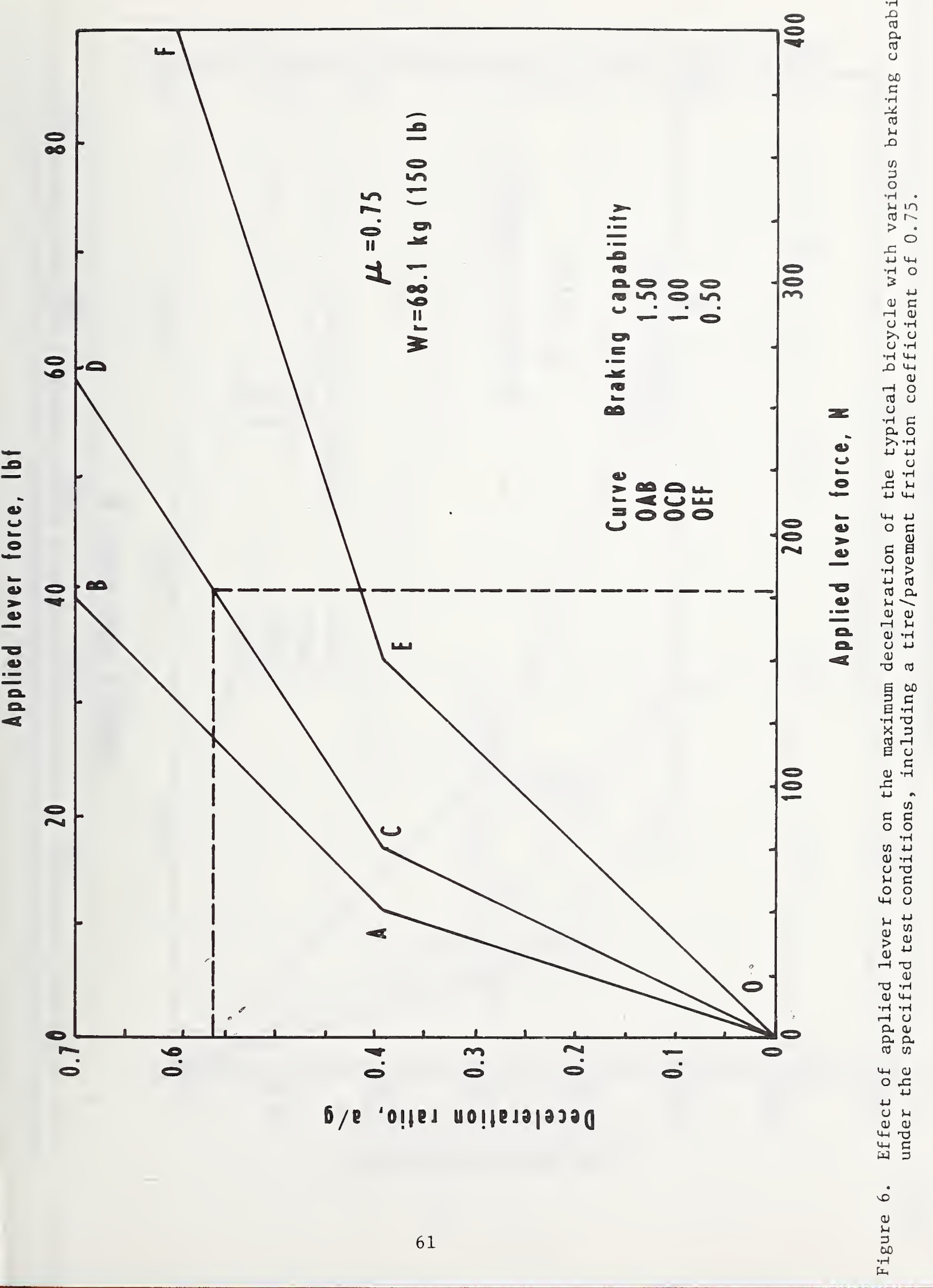




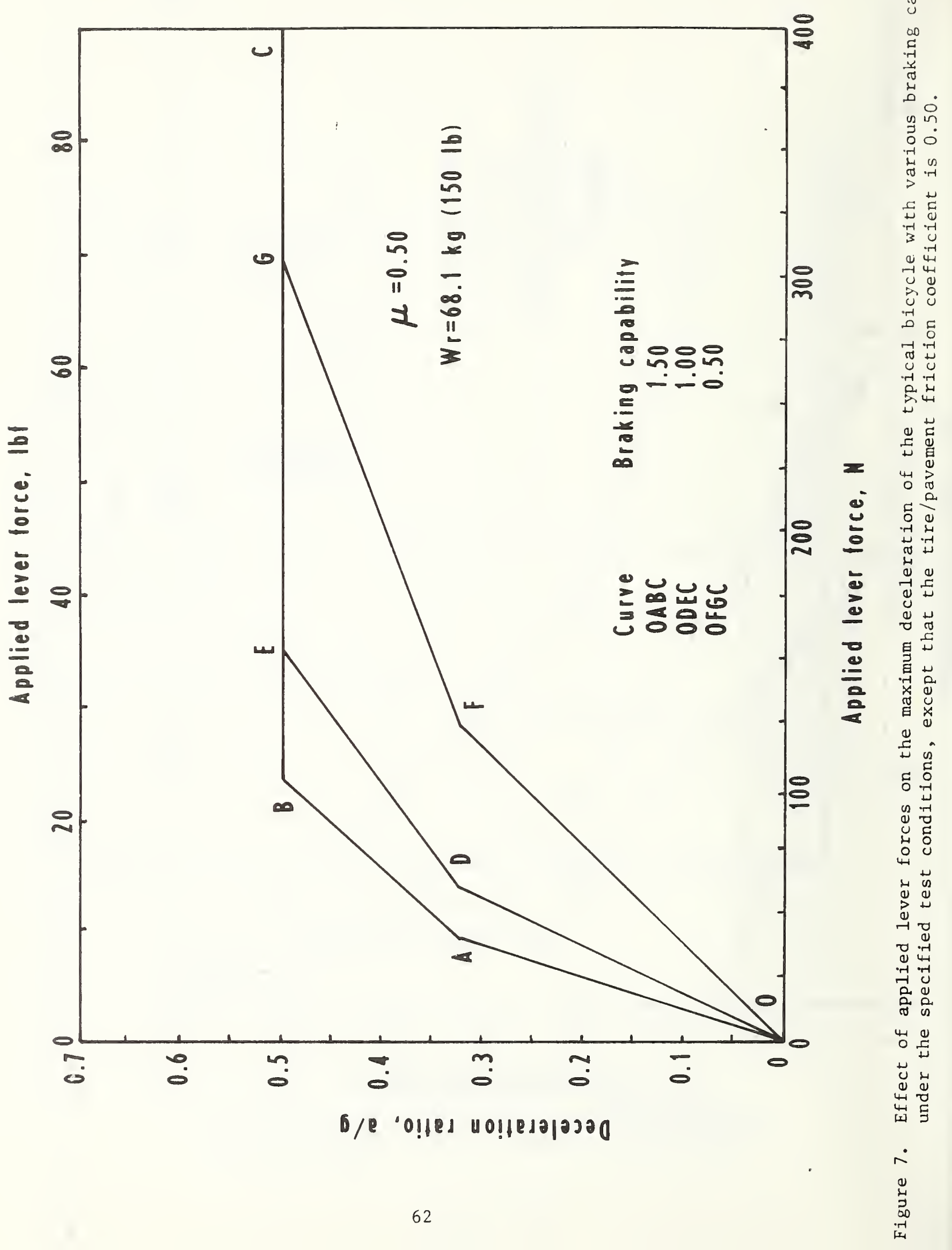




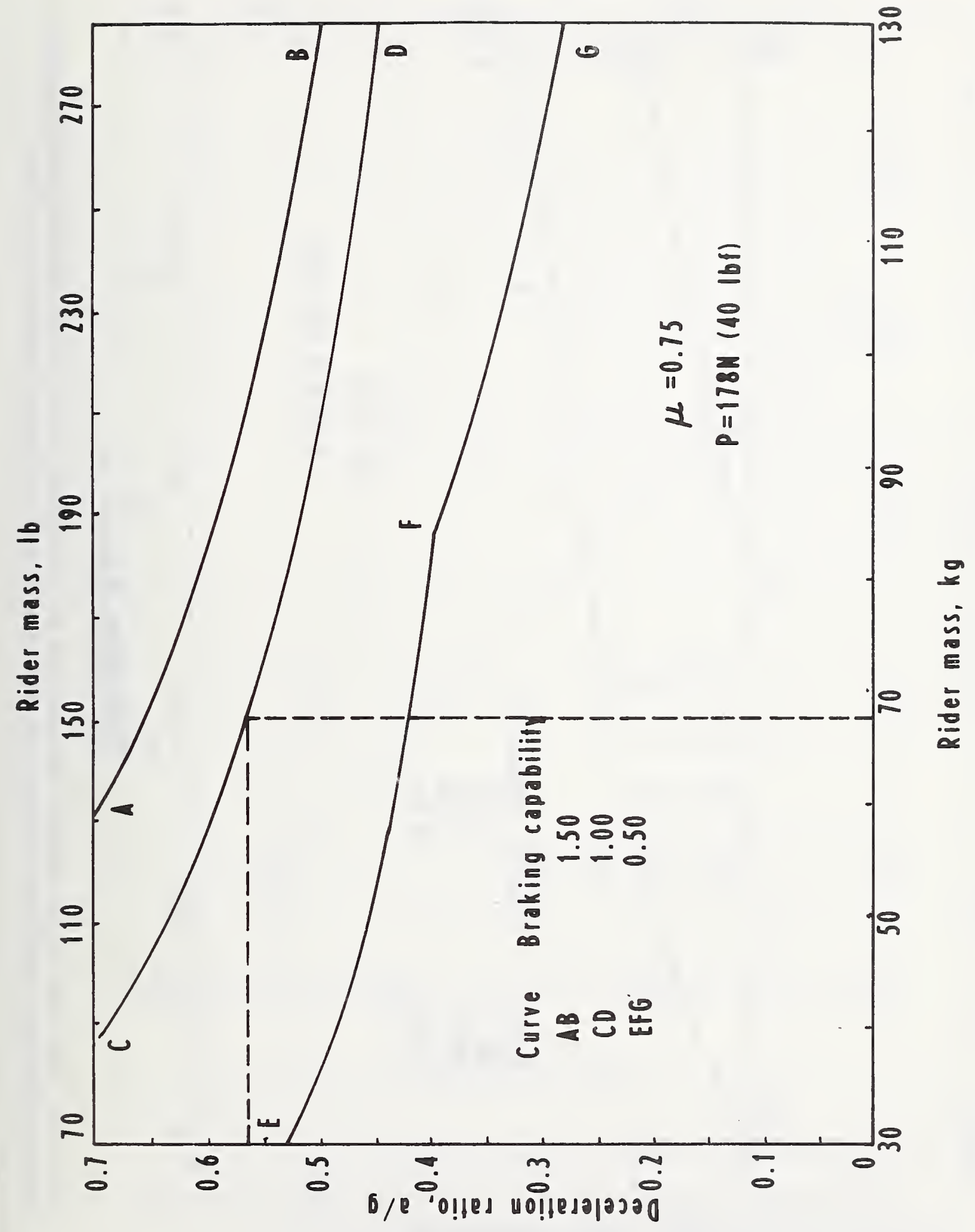

तै

م. 다

त

- $\stackrel{2}{5}$

$-4$

$\sim$ ก

䛼 皇

'

范

¿

步

동 몽

us

皆岕

$4+$ वृ प4- 0 虫 品 a) 峠出 


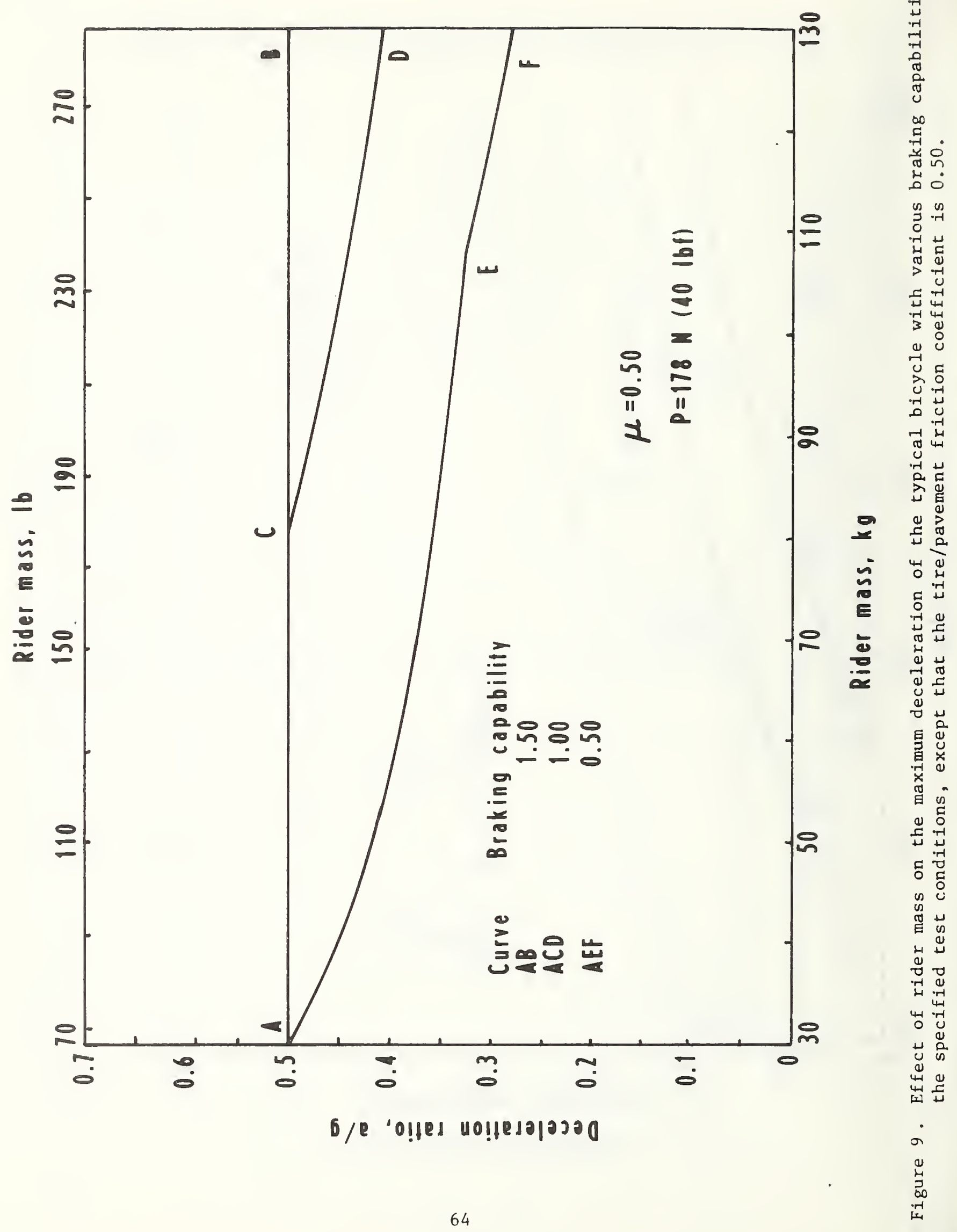




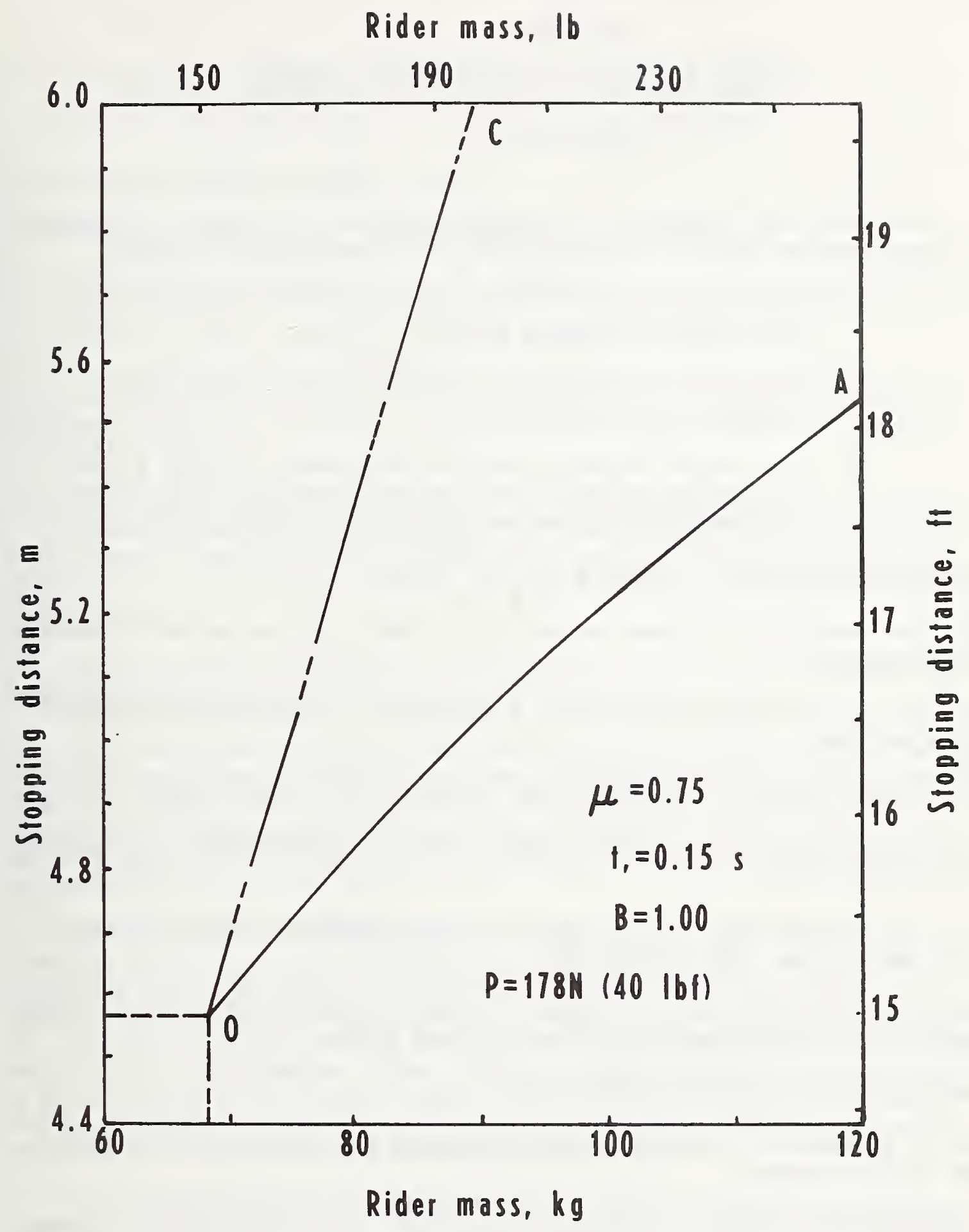

Figure 10. Effect of rider mass on the stopping distance of the typical bicycle with marginal braking capability under the specified test conditions, including a tire/pavement friction coefficient of 0.75 . 
ERROR ANALYSES OF THREE SPECIFIC SYSTEMS

December 1975

Following the completion of the main text of this report, the author was requested to prepare error analyses for three specific systems:

A. The system used by NBS in the series of tests described in a companion report [13].

B. The system required by a recent revision [30] of the Bicycle Safety Regulation.

C. The "ideal" system, which is interpreted to mean a road testing system which would incorporate all of the best recommendations proposed in the main text of this report.

The characteristics of System $A$ were as follows:

(1) The starting point was located with a paint gun activated by powerful electromagnets.

(2) The bicycle was steered along a relatively straight path into the stopping zone.

(3) Bicycle speed was measured with an electronic timing trap.

(4) The pavement of the test course offered a tire/pavement friction coefficient of 1.22 .

(5) The combined mass of the rider and instrumentation varied between 74.4 and $99.8 \mathrm{~kg}$ (164 and $220 \mathrm{lb}$ ).

(6) Alternate test runs were made in opposite directions and the results averaged to minimize errors due to wind and grade.

The characteristics of System B are:

(1) A transverse line marker on the pavement may be used to designate the starting point.

(2) The bicycle must be moving in a straight line at the start of brake application.

(3) Bicycle speed may be measured with a speedometer.

(4) The pavement of the test course must be such that it offers a tire/pavement friction coefficient of less than 1.0 , but more than the threshold value for front-wheel lockup. 
(5) The combined mass of the rider and the instrumentation may not exceed $91 \mathrm{~kg}(200 \mathrm{lb})$.

(6) The slope of the test course shall not exceed 1 percent.

(7) The wind velocity shall not exceed $3.0 \mathrm{~m} / \mathrm{s}$ (7 mph).

The characteristics of System $C$ are:

(1) The starting point is located with propelled markers.

(2) The bicycle is steered along a straight path into the stopping zone.

(3) Bicycle speed is measured with an electronic timing trap.

(4) The pavement of the test course offers a tire/pavement friction coefficient which is less than 1.0 but more than the threshold value for front-wheel lockup.

(5) The combined mass of the rider, the instrumentation and added mass (if needed) is fixed at $91 \mathrm{~kg}(200 \mathrm{lb})$. (This changes the required stopping distance for the typical bicycle with marginal braking capability from 4.57 to $5.05 \mathrm{~m} \mathrm{(} 15.0$ to $16.6 \mathrm{ft}$ ) and eliminates the overwelght rider allowance).

(6) Alternate test runs are made in opposite directions and the results averaged to minimize errors due to wind and grade.

The random and systematic error bands corresponding to these charactersitics are given in Table A together with those for the example system (System $X$ ) discussed in Section 13.2, for comparison. Also given in the table are the probable overall error bands for each system, calculated as the square root of the sum of the squares of the individual errors, as described in the main text.

It may be seen that the probable overall random error bands for Systems $A$ and $C$ are not significantly different from that for System $X$ since the principal source of random error, namely, the variability in rider reaction times, is the same in all three systems. The probable overall random error band for system B is considerably larger than this, however, because this system allows additional major sources of random error by permitting a starting line rather than propelled markers to be used for indicating the starting point, and by permitting speedometers rather than timing traps to be used for speed measurement.

The probable overall systematic error band for System $A$ is narrower than that for System $X$ since the combined masses of rider and instrumentation were limited to the range of 74.4 to $99.8 \mathrm{~kg}$ (164 to $220 \mathrm{lb}$ ) in System A. The probable overall systematic error band for System $B$ is better yet, since this system limits the combined mass of the rider and the instrumentation to maximum of $91 \mathrm{~kg}(200 \mathrm{lb})$. However, the probable overall systematic 
error band for System $C$ is by far the best of all since in this system all bicycles are tested with the same payload, consisting of the combined masses of the rider, the instrumentation, and added mass as needed, to attain the specified total. 

Table A - Error Analyses of Specific Systems as Applied to a Typical Bicycle with

\begin{tabular}{|c|c|c|c|c|}
\hline \multirow[b]{2}{*}{$\begin{array}{c}\text { Source of } \\
\text { error }\end{array}$} & \multicolumn{2}{|c|}{$\begin{array}{r}\text { System } \mathrm{A} \\
\end{array}$} & \multicolumn{2}{|c|}{ System B } \\
\hline & $\begin{array}{l}\text { systematic } \\
\text { error }\end{array}$ & $\begin{array}{r}\text { random } \\
\text { error }\end{array}$ & $\begin{array}{c}\text { systematic } \\
\text { error } \\
\end{array}$ & $\begin{array}{l}\text { random } \\
\text { error }\end{array}$ \\
\hline & $\begin{array}{c}\mathrm{m} \\
(\mathrm{ft})\end{array}$ & $\begin{array}{c}m \\
(f t)\end{array}$ & $\begin{array}{c}\mathrm{m} \\
(\mathrm{ft})\end{array}$ & $\begin{array}{c}m \\
(f t)\end{array}$ \\
\hline Start location & $\begin{array}{l}-0.1<b<0 \\
(-0.3<b<0)\end{array}$ & $\begin{array}{l}-0.02<r<0.02 \\
(-0.07<r<0.07)\end{array}$ & $\begin{array}{c}0 \\
(0)\end{array}$ & $\begin{array}{l}-0.6<r<0.6 \\
(-2 \quad<r<2)\end{array}$ \\
\hline Steering & $\begin{array}{c}0 \\
(0)\end{array}$ & $\begin{array}{l}-0.04<r<0 \\
(-0.1<r<0\end{array}$ & $\begin{array}{c}0 \\
(0)\end{array}$ & $\begin{array}{l}-0.04<r<0 \\
(-0.1<r<0\end{array}$ \\
\hline Reaction time & $\begin{array}{c}0 \\
(0)\end{array}$ & $\begin{array}{l}-0.39<r<0.89 \\
(-1.3<r<2.9)\end{array}$ & $\begin{array}{c}0 \\
(0)\end{array}$ & $\begin{array}{l}-0.39<r<0.89 \\
(-1.3<r<2.9)\end{array}$ \\
\hline Speed measurement & $\begin{array}{l}-0.12<b<-0.10 \\
(-0.4<b<-0.3)\end{array}$ & $\begin{array}{l}-0.09<r<0.09 \\
(-0.3<r<0.3)\end{array}$ & $\begin{array}{c}0 \\
(0)\end{array}$ & $\begin{array}{l}-0.27<\boldsymbol{r}<0.27 \\
(-0.9<\boldsymbol{r}<0.9)\end{array}$ \\
\hline Pavement friction & $\begin{array}{l}-0.18 \\
(-0.6)\end{array}$ & $\begin{array}{c}0 \\
(0)\end{array}$ & $\begin{array}{l}-0.12<b<0.12 \\
(-0.4<b<0.4)\end{array}$ & $\begin{array}{c}0 \\
(0)\end{array}$ \\
\hline Handlever forces & $\begin{array}{l}-0.03<b<0.11 \\
(-0.1<b<0.4)\end{array}$ & $\begin{array}{l}-0.11<r<0.11 \\
(-0.4<r<0.4)\end{array}$ & $\begin{array}{l}-0.03<b<0.11 \\
(-0.1<b<0.4)\end{array}$ & $\begin{array}{l}-0.11<r<0.11 \\
(-0.4<r<0.4)\end{array}$ \\
\hline Mass effects & $\begin{array}{l}-1.66<b<-0.35 \\
(-5.4<b<-1.1)\end{array}$ & $\begin{array}{c}0 \\
(0)\end{array}$ & $\left.\begin{array}{l}-1.05<b<0 \\
(-3.4<b<0\end{array}\right)$ & $\begin{array}{c}0 \\
(0)\end{array}$ \\
\hline Inclined roadway & $\begin{array}{c}0 \\
(0)\end{array}$ & $\begin{array}{c}0 \\
(0)\end{array}$ & $\begin{array}{l}-0.08<b<0.08 \\
(-0.3<b<0.3)\end{array}$ & $\begin{array}{c}0 \\
(0)\end{array}$ \\
\hline Wind effects & $\begin{array}{c}0 \\
(0)\end{array}$ & $\begin{array}{l}-0.10<\mathrm{r}<0 \\
(-0.3<\mathrm{r}<0\end{array}$ & $\begin{array}{c}0 \\
(0)\end{array}$ & $\begin{array}{l}-0.09<r<0.04 \\
(-0.3<r<0.1)\end{array}$ \\
\hline Probable overall & $\begin{array}{l}-1.68<\overline{\mathrm{b}}<-0.39 \\
(-5.5<\overline{\mathrm{b}}<-1.3)\end{array}$ & $\begin{array}{l}-0.43<\overline{\mathbf{r}}<0.90 \\
(-1.4<\overline{\mathbf{r}}<3.0)\end{array}$ & $\begin{array}{l}-1.06<\overline{\mathrm{b}}<0.18 \\
(-3.5<\overline{\mathrm{b}}<0.6)\end{array}$ & $\begin{array}{l}-0.78<\overline{\mathbf{r}}<1.11 \\
(-2.6<\bar{r}<3.6)\end{array}$ \\
\hline
\end{tabular}




\begin{tabular}{|c|c|c|c|}
\hline \multicolumn{2}{|c|}{ System C } & \multicolumn{2}{|c|}{ System X } \\
\hline systematic & random & systematic & random \\
\hline error & error & error & error \\
\hline $\begin{array}{c}m \\
(f t)\end{array}$ & $\begin{array}{l}m \\
(f t)\end{array}$ & $\begin{array}{l}\mathrm{m} \\
(\mathrm{ft})\end{array}$ & $\begin{array}{l}\mathrm{m} \\
(\mathrm{ft})\end{array}$ \\
\hline
\end{tabular}

$\begin{array}{cccc}-0.2<\mathrm{b}<0 & -0.02<r<0.02 & -0.2<\mathrm{b}<0 & -0.02<r<0.02 \\ (-0.7<b<0) & (-0.07<r<0.07) & (-0.7<b<0) & (-0.07<r<0.07) \\ 0 & -0.04<r<0 & & -0.04<r<0 \\ (0) & (-0.1<r<0) & 0 & (-0.1<r<0) \\ 0 & -0.39<r<0.89 & (0) & -0.39<r<0.89 \\ (0) & (-1.3<r<2.9) & 0 & (-1.3<r<2.9)\end{array}$

$-0.12<b<-0.10$

$(-0.4<b<-0.3)$

$-0.12<b<0.12$

$(-0.4<b<0.4)$

$-0.03<b<0.11$

$(-0.1<b<0.4)$

\section{0}

(0)

0

(0)

0

(0) $-0.09<r<0.09$
$(-0.3<r<0.3)$

0

(0)

$-0.11<r<0.11$

$(-0.4<r<0.4)$

0

(0)

0

(0)

$-0.10<r<0$

$(-0.3<r<0)$ $-0.12<b<-0.10$

$(-0.4<b<-0.3)$

$-0.12<b<0.12$

$(-0.4<b<0.4)$

$-0.03<b<0.11$

$(-0.1<b<0.4)$

$-2.50<b<0$

$(-8.2<b<0) \div$

0

(0)

0

(0) $-0.09<\mathrm{r}<0.09$

$(-0.3<\mathrm{r}<0.3)$

0

(0)

$-0.11<r<0.11$ $(-0.4<r<0.4)$

0

(0)

0

(0)

$-0.15<r<0.06$

$(-0.5<r<0.2)$ $-0.26<\overline{\mathrm{b}}<0.13$

$(-0.9<\bar{b}<0.4)$ $-0.43<\bar{r}<0.90$

$(-1.4<\overline{\mathrm{I}}<3.0)$ $-2.51<\overline{\mathrm{b}}<0.13$

$(-8.2<\bar{b}<0.4)$ $-0.44<\bar{r}<0.91$

$(-1.4<\bar{I}<3.0)$ 
NBS.114A (REV.7.73)

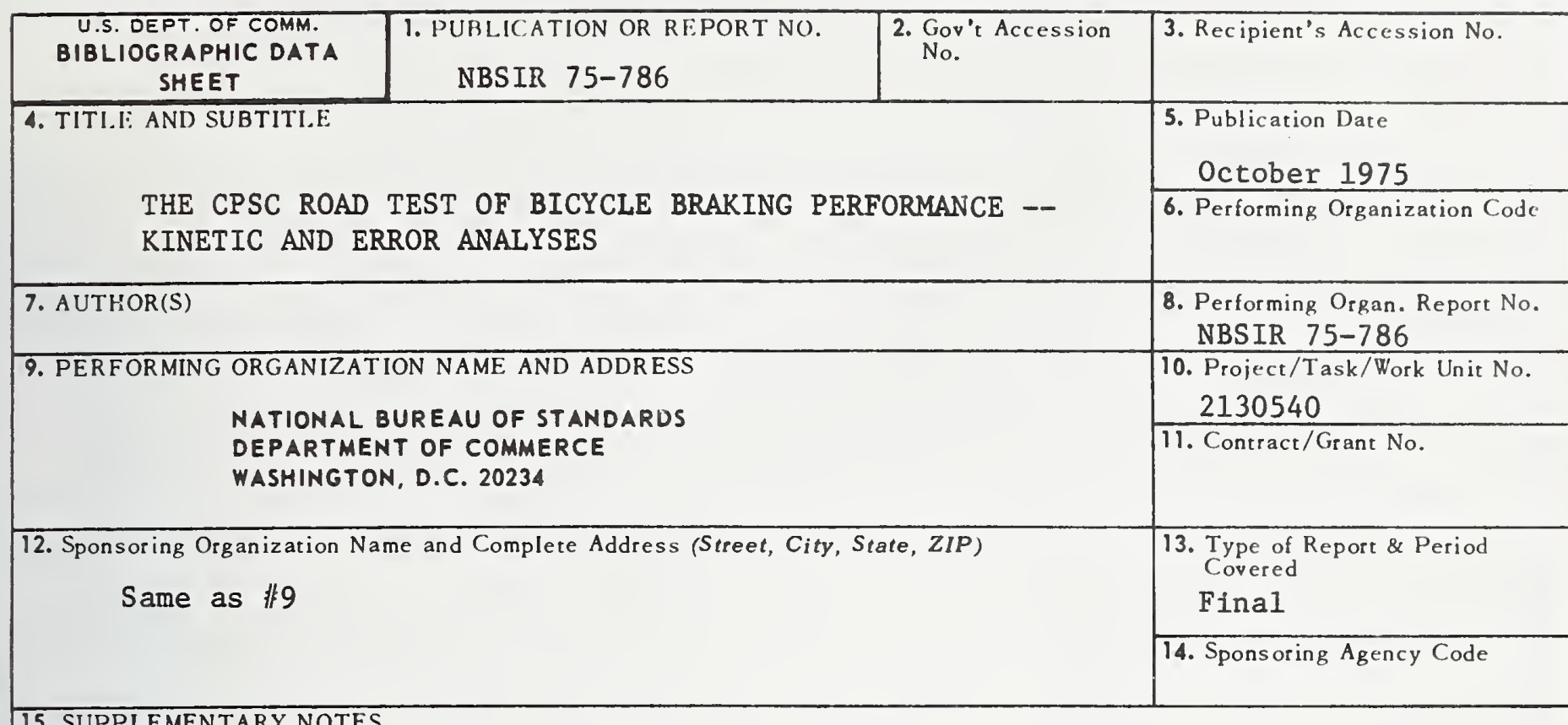

15. SUPPLEMENTARY NOTES

16. ABSTRACT (A 200-word or less factual summary of most significant information. If document includes a significant bibliography or literature survey, mention it here.)

The Consumer Product Safety Commission has promulgated a safety standard for bicycle braking systems based on the stopping distances achieved in road tests under specified conditions. This report presents an error analysis of the test method, for the Commission's use in justifying or modifying the test criteria. The error analysis is based on experimental data, for the most part, and on theoretical principles where sufficient data are lacking. The theory, a kinetic analysis of the bicycle braking process, is included in the report together with proposed definitions of terms intended to quantify important aspects of bicycle braking performance.

The error analysis produced estimates of rather large lab-to-lab and test-totest variabilities to be expected from the test method. These, in turn, were found to be principally dominated by errors resulting from an incorrect overweight-rider allowance specified by the Commission, and by variations in rider reaction times, respectively. Suggestions are made for more accurate methods of accommodating variations in rider mass, for reducing the effects of the test-to-test variability, and for reducing the danger of pitchover in the performance of the road test.

17. KEY WORDS (six to twelve entries; alphabetical order; capitalize only the first letter of the first key word unless a proper name; separated by semicolons)

Bicycle brakes; brakes, bicycle; dynamics, bicycle; error analysis; friction, tire/pavement; kinetics, bicycle; measurements, bicycle braking; pitchover; standards, bicycle safety; test method, bicycle.

18. AVAILABILITY FJ Unlimited

For Official Distribution. Do Not Release to NTIS

Order From Sup. of Doc., U.S. Government Printing Office Washington, D.C. 20402, SD Cat. No. C13

\begin{tabular}{|c|c|}
\hline $\begin{array}{l}\text { 19. SECURITY CL ASS } \\
\text { (THIS REPURT) } \\
\text { UNCL ASSIFIED }\end{array}$ & $\begin{array}{l}\text { 21. NO. OF PAGES } \\
74\end{array}$ \\
\hline $\begin{array}{l}\text { 20. SECURITY CLASS } \\
\text { (THIS PAGE) } \\
\text { UNCLASSIFIED }\end{array}$ & $\begin{array}{l}\text { 22. Price } \\
\$ 4.50\end{array}$ \\
\hline
\end{tabular}

X Order From National Technical Information Service (NTIS) Springfield, Virginia 22151 

